\title{
Land cover and socioeconomic factors explain avian diversity in a tropical megacity
}

\author{
Marufa Sultana $^{1}$, Ilse Storch ${ }^{1}, \underline{M}_{\text {. Niamul Naser }}{ }^{2}{\text { and Mayeen } \text { Uddin }^{3}}^{3}$
}

\begin{abstract}
Factors driving urban biodiversity remain poorly documented in the rapidly growing tropical cities. We investigated the drivers of bird diversity in Dhaka city, located in Bangladesh, South Asia. Using existing sources, we compiled a bird checklist of the city. Next, we conducted point-count surveys of birds across its urban areas. Using field survey data, we investigated urban land cover and socioeconomic effects on resident bird species richness and abundance by applying linear regression modeling. Additionally, we performed path analyses for an in-depth understanding of direct and indirect relationships between selected urban land covers and socioeconomic variables and bird diversity. Our linear regression model assessment indicated that land cover is significantly shaping resident bird richness, whereas bird abundance is influenced by the combined effect of land cover and socioeconomic factors. Specifically, an increasing proportion of imperviousness was causing low bird richness, whereas bird abundance increased in areas with high habitat heterogeneity and proximity to parks but decreased with rising poverty (one of the major socioeconomic issues in Dhaka). Causal path analysis revealed that socioeconomic status, directly as well as indirectly mediated by urban land cover factors, affects bird diversity. Most importantly, it confirmed the greater significance of the direct negative effect of imperviousness on bird richness and of poverty on bird abundance in urban areas. This, in turn, suggests that bird diversity is favored by heterogeneous habitats and in wealthier neighborhoods. Nevertheless, overall bird diversity in Dhaka city was largely made up of generalist species of low conservation concern; species of the omnivore feeding guild and with ubiquitous habitat preferences were the most abundant. Our results represent the first step toward understanding drivers of biodiversity patterns across urban areas of tropical megacities within South Asia and contribute to a solid basis for urban biodiversity planning in the region.
\end{abstract}

Key Words: bird; conservation; imperviousness; poverty; South Asia; urbanization

\section{INTRODUCTION}

Urbanization alters bird species composition in cities, resulting in a higher abundance of species of low conservation concern in urban centers and highly built-up areas (McKinney 2002, Garaffa et al. 2009, Silva et al. 2015, Callaghan et al. 2019). Generalist species are highly flexible in the human-altered environment and plausibly replace native specialist species as urbanization proceeds (McKinney 2008, Rodewald and Gehrt 2014, Callaghan et al. 2019). Thus, avian diversity generally declines in highly urbanized areas, largely because of the loss of green habitat patches caused by the increasing extent of human settlement (Tratalos et al. 2007, Gagné and Fahrig 2011, Silva et al. 2015). Nevertheless, bird richness can be high in highly built-up areas if habitat heterogeneity also increases (Evans et al. 2009, Sultana et al. 2021). Suburban areas can favor a complex bird community because of varying levels of land-use intensity, lower predation pressure, and availability of artificial resources (Blair 2001, Marzluff 2005, Evans et al. 2007, McKinney 2008, Muller et al. 2010, Verma and Murmu 2015). Furthermore, aspects of human behavior and social status also affect bird diversity. Avian diversity can be high in (sub-)urban neighborhoods of high socioeconomic status (Kinzig et al. 2005, Melles 2005, Strohbach et al. 2009, Leong et al. 2018), where property owners' decisions often result in a mixed suburban structure with large private gardens (Nilon 2014).

Despite some conceptual understanding of urban biodiversity patterns, the key driving factors of bird diversity in tropical cities are not well documented (Grimm et al. 2008, Faeth et al. 2011,
Aronson et al. 2014). We focused on birds in the South Asian megacity of Dhaka, which is the capital and largest city of Bangladesh. Urbanization in South Asia has been called "messy and hidden," reflecting the 130 million people living in poverty in low-quality housing, i.e., slums (Ellis and Roberts 2016). It also reflects the rapidly rising proportion of the urban population, largely due to rural-urban migration, and built-up areas across and beyond the limits of many cities (such as Dhaka, Delhi, Karachi, and Mumbai) in this region (Ellis and Roberts 2016). Among all South Asian cities, Dhaka is experiencing the fastest urban growth and is forecasted to be the sixth most crowded city, with a population of over 20 million by 2030 (UN 2014). In annual reports by Demographia during 2016-2020, it is continually ranked first among 1022 built-up urban areas worldwide, based on urban population density per $\mathrm{km}^{2}$ (http://www.demographia. com/db-worldua.pdf). This increasing level of urbanization is placing both human well-being and biodiversity at high risk. In light of this concern, assessing factors driving the populations of birds and other components of biodiversity in Dhaka would provide a model example for South Asian cities experiencing similar massive urban growth.

In Dhaka, existing ecological research has mostly focused on land cover change (Sultana et al. 2009, Byomkesh et al. 2012, Dewan et al. 2012, Jaman et al. 2020, Rahman and Szabó 2021), climatic effects and environmental pollution (Dewan et al. 2021, Uddin and Jeong 2021), and economic and social aspects (Zinia and McShane 2018). Several such studies have reported that the high intensity of population growth and extent of human settlement

${ }^{1}$ Wildlife Ecology and Management, Faculty of Environment and Natural Resources, University of Freiburg, Germany, ${ }^{2}$ Department of Zoology, Faculty of Biological Sciences, University of Dhaka, Bangladesh, ${ }^{3}$ Department of Zoology, Narsingdi Government College, Bangladesh 
have already caused a significant alteration in abiotic conditions, deficiency in natural vegetation cover, and loss in green spaces and wetland areas in this city (Sultana et al. 2009, Byomkesh et al. 2012, Jaman et al. 2020, Dewan et al. 2021). Inadequate urban planning not only led to a rapid alteration of ecologically important land cover features but also fueled greater inequality in socioeconomic status (Ahamed and Hasan 2010, UN-Habitat 2020). It is largely unknown how the altered urban land cover and socioeconomic conditions are driving different components of biodiversity along the gradient of urbanization within Dhaka city. A basis for urban biodiversity conservation planning within Dhaka city is lacking.

Birds can be observed easily and are a useful indicator of biodiversity within cities (Strohbach et al. 2009). Thus, the presence of healthy bird diversity (i.e., a high proportion of native species) can be positive evidence of green and sustainable growth in a city (Chace and Walsh 2006, Evans et al. 2009, Silva et al. 2015). In Dhaka city, birds are the best-surveyed taxon; multiple studies have compiled bird checklists for urban parks, botanical gardens, and university campus areas (Islam et al. 2014, Shovon et al. 2014, Rajia et al. 2015, Banu et al. 2016). However, very few existing avian studies in Dhaka have accounted for urbanization effects (Sarker et al. 2009). We attempted to provide insights on avian diversity as a proxy for overall biodiversity in Dhaka city. Our major focus was to gain knowledge on the driving factors of resident bird diversity (richness and abundance) in this city.

Existing studies suggest that birds' flexibility and adaptability to urban settings vary along a gradient of urbanization (Rodewald and Gehrt 2014); one guild of bird species may tend to increase, whereas others decrease in urban areas (Luck and Smallbone 2010). In light of this, we first explored dissimilarities in bird diversity across built-up areas. We hypothesized that birds of the omnivorous feeding guild and birds with generalist and opportunistic habitat use would be the most abundant.

Earlier studies indicated that human attitudes and behaviors toward wildlife tend to correlate with socioeconomic status within a community, with wealthier and better-educated populations showing more mutualistic, i.e., conservation-minded, value orientations (Manfredo 2008, Nilon 2014). Thus, bird diversity is affected not only by land cover, but also by socioeconomic factors in urban neighborhoods, and this may vary within cities (Kinzig et al. 2005, Melles 2005, Loss et al. 2009, Strohbach et al. 2009, Kendal et al. 2012, Meléndez-Ackerman et al. 2014). We, therefore, assessed bird species richness and abundance patterns in Dhaka city using urban land cover and socioeconomic explanatory variables. We hypothesized that avian diversity, i.e., bird species richness and abundance, in Dhaka declines not only with increasing proportions of build-up areas but also with increasing poverty, which is one of the major socioeconomic issues in this tropical city.

\section{METHODS}

\section{Study area}

We conducted our study in the central city region of Dhaka (Fig. 1), which accounts for $63.22 \%$ of the total population of its greater metropolitan area. The average population density is 325 people per hectare in this area but is in fact much higher (799 people per hectare) in residential areas (RAJUK 2015). Within Dhaka city, the rapid increase in human population and built-up areas over the last few decades has resulted in a reduction of agricultural areas, water bodies, and green areas (Byomkesh et al. 2012, Dewan et al. 2012, Khaleda et al. 2017). The existing urban area is made up of $41.45 \%$ residential areas, $21.42 \%$ agricultural areas, $13.03 \%$ water bodies, $0.95 \%$ recreational areas (such as parks, playgrounds, and urban green areas), and $23.15 \%$ other land use (such as roads and railways and restricted, commercial, industrial, mixed-use, and public facility areas; RAJUK 2015).

\section{Bird diversity}

We collected available human (i.e., non-automated) observation records of birds from existing literature, Global Biodiversity Information Facility (http://www.gbif.org), and eBird (http:// www.ebird.com) for the period 1995-2017. Further, we conducted a single-season bird survey during February-June 2018 at 190 locations distributed along a built-up gradient in the city. Because of the many restricted and private sites in the city, our field survey locations were mostly made up of public sites that were easily accessible. At these locations, we surveyed birds following the widely used fixed-radius point-count method (Bibby et al. 2000, Gregory et al. 2004). The locations were surveyed for 1-3 days, nonconsecutively, during early morning and late afternoon. At each point location, we conducted visual and aural inspection within an approximate radius of $50 \mathrm{~m}$ and documented all bird species seen or heard over 10-15 minutes on the spot.

Based on existing records and our field observations, we compiled a general bird checklist of the city. For each species, we listed the scientific name along with its local (IUCN Bangladesh 2015) and global (http://www.iucnredlist.org) status as described in IUCN. We cross-checked the occurrence extent of each bird using BirdLife International's species range maps (http://datazone. birdlife.org/species/requestdis). For species whose status in the city was ambiguous, we consulted multiple local experts to confirm presence. We removed all species for which scientific and English names did not match (i.e., species identity was unclear) in the existing source. Further, we considered only the bird species that are considered wild, i.e, self-sustaining, at the country level assessment in Bangladesh (IUCN Bangladesh 2015).

Next, using our field-collected data, we compared bird assemblages across different classes of built-up areas and green areas within the city. Field observations did not cover multiple seasons; thus, we concentrated only on resident species, i.e., native and nonmigratory. For each resident species, we noted diet, occurrence range, and habitat (IUCN Bangladesh 2015). From this, we broke down feeding guilds into seven categories: omnivores, insectivores, carnivores, granivores, frugivores, piscivores, and nectarivores. For each species, we also categorized habitat preferences for foraging as follows: (1) ubiquitous (i.e., the species occurs everywhere and uses all habitat types for foraging); (2) woody vegetation (i.e., the species prefers open woodland, roadside trees, parks, and botanical gardens); (3) wetlands (i.e., the species prefers sites near ponds, lakes, rivers, or other wetlands); (4) cropland, grassland (i.e., the species prefers cultivated land and open areas with short/tall grasses); or (5) cropland, human habitation (i.e., the species prefers cultivated land and human habitation sites). We plotted the rank abundance curve (Colwell 2009) to identify common and rare species and variability across different families, feeding guilds, and habitat

Erratum: The reference and link to Global Biodiversity Information Facility (http://www.gbif.com) were incorrect in the original version of this manuscript. The error was corrected on 25 March 2022. 
Fig. 1. Bird survey locations within Dhaka city. Note that point symbols are enlarged to improve visibility. The map shows the World Street Map as a base layer. The geographic coordinate system is GCS_WGS_1984 on the map.

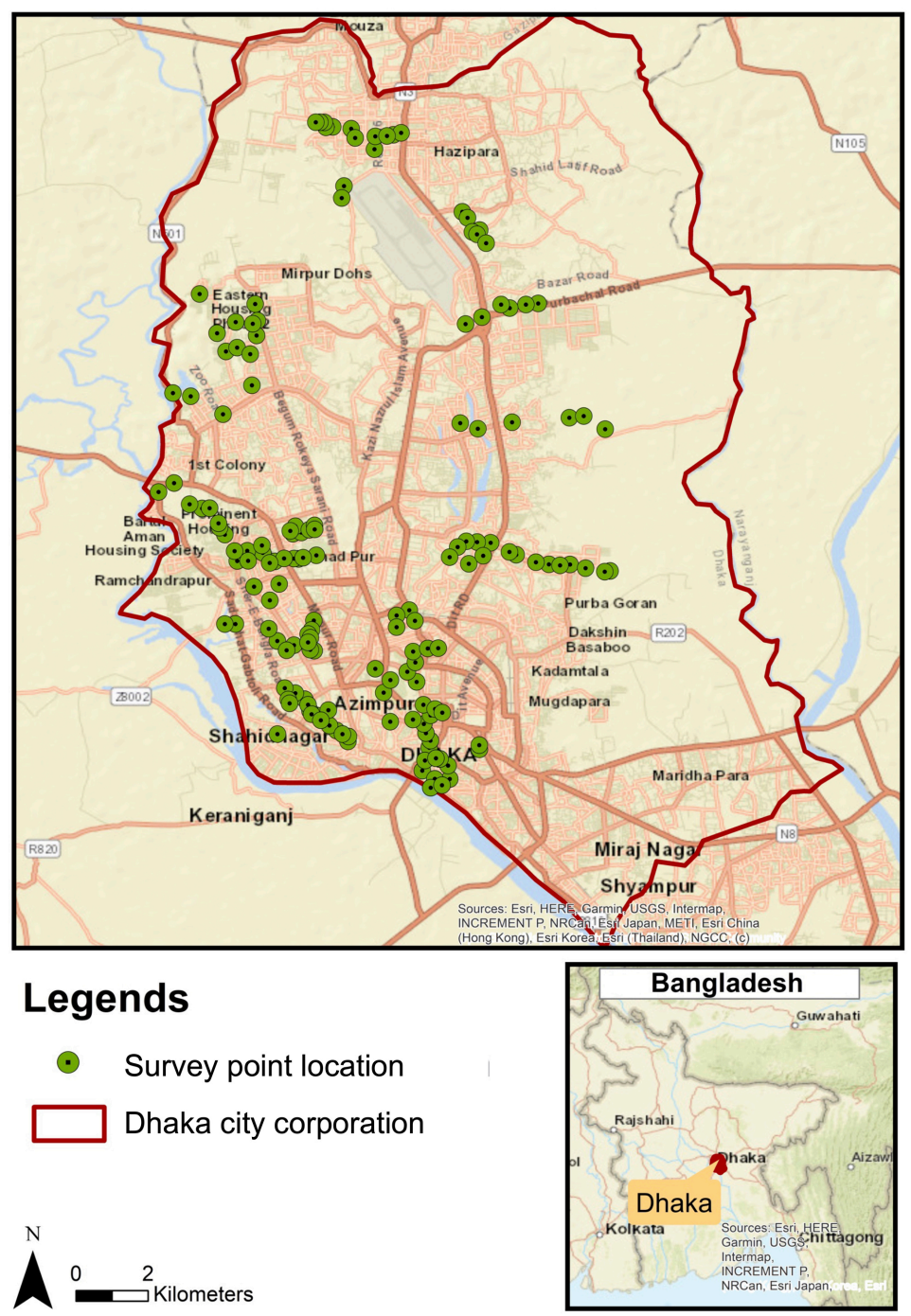

preferences for foraging across urban areas in Dhaka. Further, we estimated the incidence rate for each resident bird species, which we classed as follows: $1=$ abundant $(>50$ occurrences $) ; 2=$ common (10-50 ocurrences); $3=$ uncommon/rare $(<10$ occurrences). Using boxplots, we inspected the distribution of the number of total species and total individuals under these distinct classes across different gradients of built-up and urban green areas. Additional exploration of urban affinity of the observed birds is available in Appendix 1.

For our major analysis, we estimated resident bird species richness (i.e., number of species) and abundance (i.e., number of individuals at the surveyed point locations). We performed model analyses to understand the major factors that drive bird species richness and abundance across urban areas in Dhaka.

\section{Drivers of bird diversity}

We inspected the relationship of resident bird species richness and abundance to nine explanatory variables (Appendix 1, Table A1.1). Five of the explanatory variables represented urban land cover effect: (1) percentage of impervious surface to account for the extent of built-up areas (IS), (2) habitat Shannon metric to account for habitat heterogeneity (HS), (3) distance to the nearest park (DP), (4) distance to the nearest water body (DW), and (5) percentage of vegetation (VG). Four of the explanatory variables indicated socioeconomic effect: (6) human population (estimated number of people; HP), (7) poverty index ratio (PI), (8) household income (IN), and (9) higher education percentage (ED). We estimated the values of the urban land cover and socioeconomic variables at each point survey location as a proxy for local 
Fig. 2. Models' diagrams showing causal relationships of the percentage of impervious surface (IS), habitat Shannon metric (HS), distance to nearest parks (DP), poverty index ratio (PI), human population (HP), and bird diversity (richness and abundance rate) in an urban neighborhood.
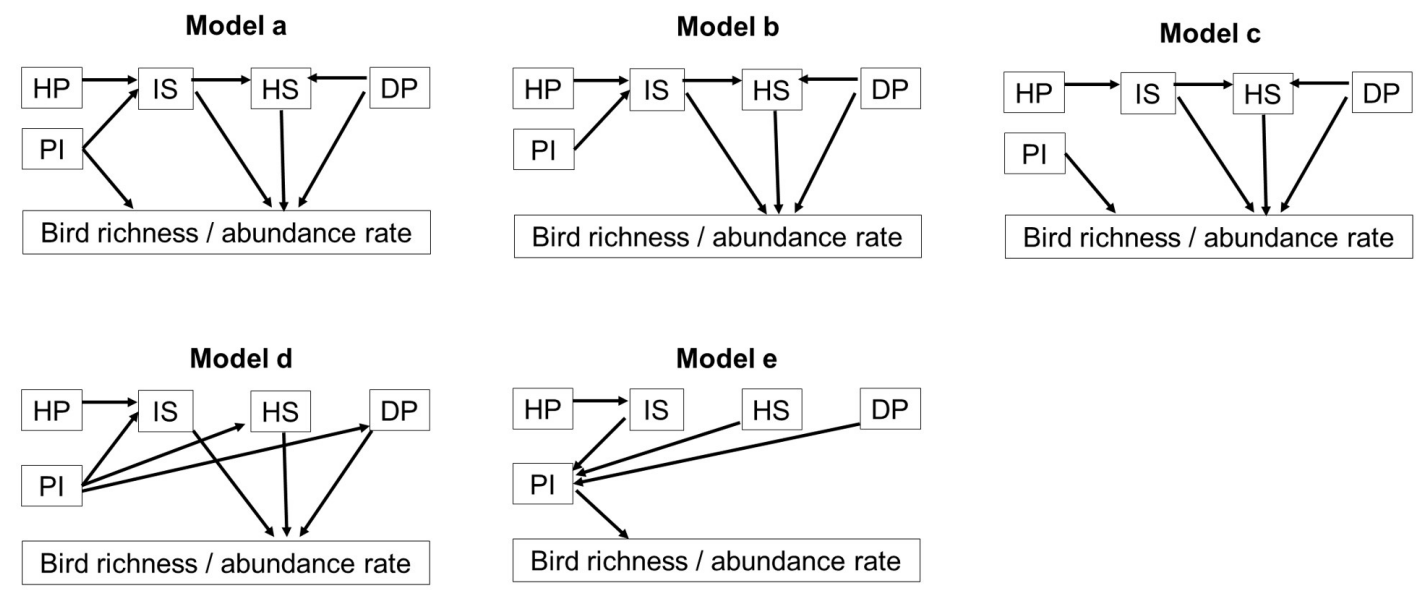

neighborhood status. We performed Pearson correlation analyses among all the variables and estimated the variance inflation factor (VIF) to check for multicollinearity issues before model assessment (i.e, if correlation value $>0.7$ and $\mathrm{VIF}>5$, severe collinearity is indicated; Dormann et al. 2013, Akinwande et al. 2015).

We observed a high positive relationship between resident bird species richness (i.e., number of species) and abundance (i.e., number of individuals), respectively, and the frequency of field surveyed days (FD). Thus, to avoid sampling-related bias, we calculated the "bird richness rate" and "bird abundance rate," dividing resident bird species richness and abundance by the FD. We considered bird richness rate and bird abundance rate as our response variables during all model assessments.

For both response variables, we first applied linear regression modeling to assess the relationship of bird richness rate and bird abundance rate, respectively, with all urban land cover and socioeconomic variables. For normality, bird richness rate and bird abundance rate were log-10 transformed in regression model assessments. However, because local-scale land cover changes often relate to socioeconomic status, regression modeling cannot disclose causalities or separate the relative influence of land cover versus socioeconomic status on bird diversity. Therefore, in a second step, we performed path analyses (Wright 1934) to investigate probable direct and indirect causal relationships among selected explanatory variables and bird richness and abundance rates.

\section{Linear regression modeling}

To assess the linear relationships between bird diversity and explanatory variables, we compared three linear regression models: (1) one global model that included all explanatory variables and indicated a combined effect of all factors on bird richness/abundance, (2) one urban land cover effect model that included only the explanatory variables related to urban land cover, (3) one socioeconomic effect model that included only the variables related to socioeconomic status. We compared the models and selected the top-ranked model based on the lowest AICc and highest Akaike weight $\left(W_{\mathrm{i}}\right)$. For the selected model, we examined the averaged coefficient parameters at $95 \%$ confidence intervals (with $2.5 \%$ and $97.5 \%$ percentile) and significance of all explanatory variables and explained variation in the model summary. For model validation, we plotted Pearson residuals versus fitted values and checked normality in residual plots; we also checked for homogeneity and autocorrelation (Zuur et al. 2013).

\section{Path analysis}

We used path analysis (Wright 1934) to assess causal paths in the relationship between selected urban land cover and socioeconomic variables and their direct and indirect effects on bird richness and abundance rates. For this, we constructed five diagrams of alternative causal models that illustrated hypothesized relationships among selected variables (Gotelli and Ellison 2013).

In the alternative models (Fig. 2, a-e), any direct and indirect relationship was assumed based on general urban ecological understanding. In models a, b, c, and d, we assumed impervious surface (IS), habitat heterogeneity (HS), and distance to nearest parks (DP; i.e., urban land cover variables) had direct effects on bird diversity (i.e., species richness rate and abundance rate). In model e, IS, HS and DP had indirect effects mediated by poverty index ratio (PI, one of the socioeconomic variables) on bird diversity. Additionally, in models a, b, and c, IS and DP had an indirect effect mediated by HS on bird diversity. In the model a, PI had both a direct effect and an indirect effect mediated by IS; in model b, PI had only indirect effect mediated by IS; in model c, PI had only a direct effect; in model d, PI had an indirect effect mediated by IS, HS, and DP on bird diversity. In all models, human population (HP, one of the socioeconomic variables) had an indirect effect mediated by IS on bird diversity.

To evaluate the causal models' $(a-e)$ fit, we checked and compared chi-square $\left(\chi^{2}\right)$ goodness-of-fit tests; we considered $\chi^{2} P$ values $>$ 0.05 as an indication of adequate fit. We also calculated the value 
Table 1. A comparison of linear regression models of resident bird richness and abundance rate. The models included global model (i.e., combined effect model), urban land cover effect model, and socioeconomic effect model. The response variables were log10(bird richness rate) and $\log 10$ (bird abundance rate). The top model is ranked based on detla AICc $(\Delta \mathrm{i})$ and Alkalaine weight ( $\left.W_{\mathrm{i}}\right)$, and shown in bold in the table. Here, IS = percentage of impervious surface, HS = habitat Shannon metric representing habitat heterogeneity, DP = distance to nearest parks DW = distance to nearest waterbody, $\mathrm{VG}=$ percentage of vegetation, $\mathrm{HP}=$ human population, $\mathrm{PI}=$ poverty index ratio, $\mathrm{IN}=$ household income, $\mathrm{ED}=$ higher education percentage.

\begin{tabular}{|c|c|c|c|c|c|c|c|c|c|c|c|c|c|c|}
\hline Model & (Int) & IS & $\mathrm{HS}$ & VG & DP & DW & HP & ED & IN & PI & $\mathrm{df}$ & $\mathrm{AICc}$ & $\Delta_{\mathrm{i}}$ & $W_{\mathrm{i}}$ \\
\hline Global & 1.58 & -0.09 & 0.02 & 0.01 & -0.04 & -0.04 & -0.07 & -0.05 & -0.04 & -0.04 & 11 & 205.2 & 0.44 & 0.42 \\
\hline Socioeconomic & 1.58 & & & & & & -0.10 & -0.04 & -0.05 & -0.01 & 6 & 208.8 & 4.04 & 0.07 \\
\hline \multicolumn{15}{|l|}{ Abundance } \\
\hline Socioeconomic & 3.19 & & & & & & -0.02 & 0.09 & 0.06 & -0.14 & 6 & 404.10 & 0.98 & 0.38 \\
\hline
\end{tabular}

of the root-mean-square error of approximation (RMSEA); if RMSEA values $<0.06$ and RMSEA $P$ values $>0.05$, we considered the model fit satisfactory (Hu and Bentler 1999, Tomer and Pugesek 2003). Furthermore, we checked the AIC values of the models; we infer a model as the best fit if the value of AIC is the lowest. In the best-fitted model, we estimated the standardized path coefficients (corresponds to effect size) to visualize the significance of the direct and indirect effect of explanatory variables on bird richness/ abundance rate.

All analyses were conducted with R 3.6.1 (R Core Team 2019) in RStudio 1.2.1335 (RStudio Team 2019) and the packages used were MASS (Venables and Ripley 2002), vegan (Oksanen et al. 2011), MuMIn (Bartoń 2020), PerformanceAnalytics (Peterson et al. 2018), and lavaan (Rosseel 2012).

\section{RESULTS}

\section{Bird diversity}

Our bird checklist for Dhaka city contained 106 species, of which 80 were resident (Appendix 2, Table A2.1). Among the resident birds, 57 species were listed as probable breeders within the city. The remainder were infrequent visitors from the city's surroundings and were mostly seen in the botanical gardens, large public parks, and green campuses. The most abundant feeding guild was insectivores, accounting for $50 \%$ of the total. The conservation status of all species recorded was Least Concern (IUCN Bangladesh 2015), a majority of which has increasing or stable populations.

During our field survey, we recorded 8123 bird individuals accounting for $60 \%$ of all the resident species ( 48 species) recorded in the city. Of all the resident species we observed, we classified 26 species as uncommon, 14 as common, and nine as abundant. The abundant species accounted for $69.6 \%$ of the total bird occurrences in the city. The three most abundant resident bird species were Corvus splendens (13.2\% of all observed individuals), Passer domesticus (13\%), and Acridotheres tristis (8\%; Fig. 3a). We recorded 13 bird orders, among which Passeriformes (69.6\%) had the highest frequency of occurrence and abundance. Of the 31 bird families we observed, the three most frequent were Sturnidae (18.8\%), Corvidae (15.1\%), and Passeridae (13\%; Fig. 3b). Of the feeding guilds of birds, the most frequent were omnivores (48.1\%), followed by insectivores $(26.3) \%$, carnivores $(9.6 \%)$, granivores $(6.4 \%)$, frugivores $(5.6 \%)$, piscivores $(3.8 \%)$, and nectarivores $(0.3 \%$; Fig. 3 c). Among the distinct foraging habitat preferences, birds with ubiquitous occurrences (i.e., occurring in all habitat types) were the most abundant (Fig. 3d), accounting for $55.4 \%$ of the total bird occurrences.

In general, the overall number of species and individuals were higher in green sites (average bird richness was 12 and abundance was 132) than in any classes of built-up sites (average bird richness was six and abundance was 34; Fig. 4a, 4b). However, omnivores and ubiquitous species were more abundant in built-up sites than in green sites (Fig. 3c, 3d). In all urban areas, any increase in the total number of species and individuals of birds was largely correlated to the rise in abundant species (Fig. 3, Fig. 4) and omnivores (Fig. 3c); uncommon species always accounted for the lowest percentage (Fig. 4c, 4d). A slight increase in some frugivore and granivore species was recorded in green sites only (Appendix 3, Table A3.1). Further findings from the urban affinity assessment of the birds are available in Appendix 3.

\section{Drivers of bird diversity}

The correlation matrix of the observed bird species richness and abundance rate with different urban land cover variables were approximately similar; notable were the negative relationships to percentage of impervious surface and distance to water bodies and the positive relationships to habitat Shannon metric and percentage of vegetation cover at the locations (Appendix 3, Fig. A3.1). However, the correlations between bird species richness and abundance rate and most of the socioeconomic variables were quite varied (Appendix 3, Fig. A3.1). Among explanatory variables, the pairwise correlation value was $\leq 0.4$ in all cases (Appendix 3, Fig A3.1). For all variables, the VIF value was also $<2$, suggesting no issues of multicollinearity in generated models.

\section{Linear regression modeling}

The model selections suggested that the highest weighted value was achieved by the urban land cover effect model (Tables 1 and 2) for bird richness rate and by the global model (i.e., a combined effect model; Tables 1 and 3) for bird abundance rate. 
Fig. 3. Rank abundance curve plots. The vertical bar represents the proportion of abundance for observed species (a), for identified bird families (b), for identified feeding guilds (c), and for identified habitat preferences of birds (d) in different classes of built-up and in green areas. Four classes of built-up areas are represented based on the percentage of impervious surface at the survey point location: $0-30 \%, 31-50 \%, 51-80 \%$, and $80-100 \%$. Green area indicates locations within public/community parks, gardens, and sites with water bodies and vegetation.

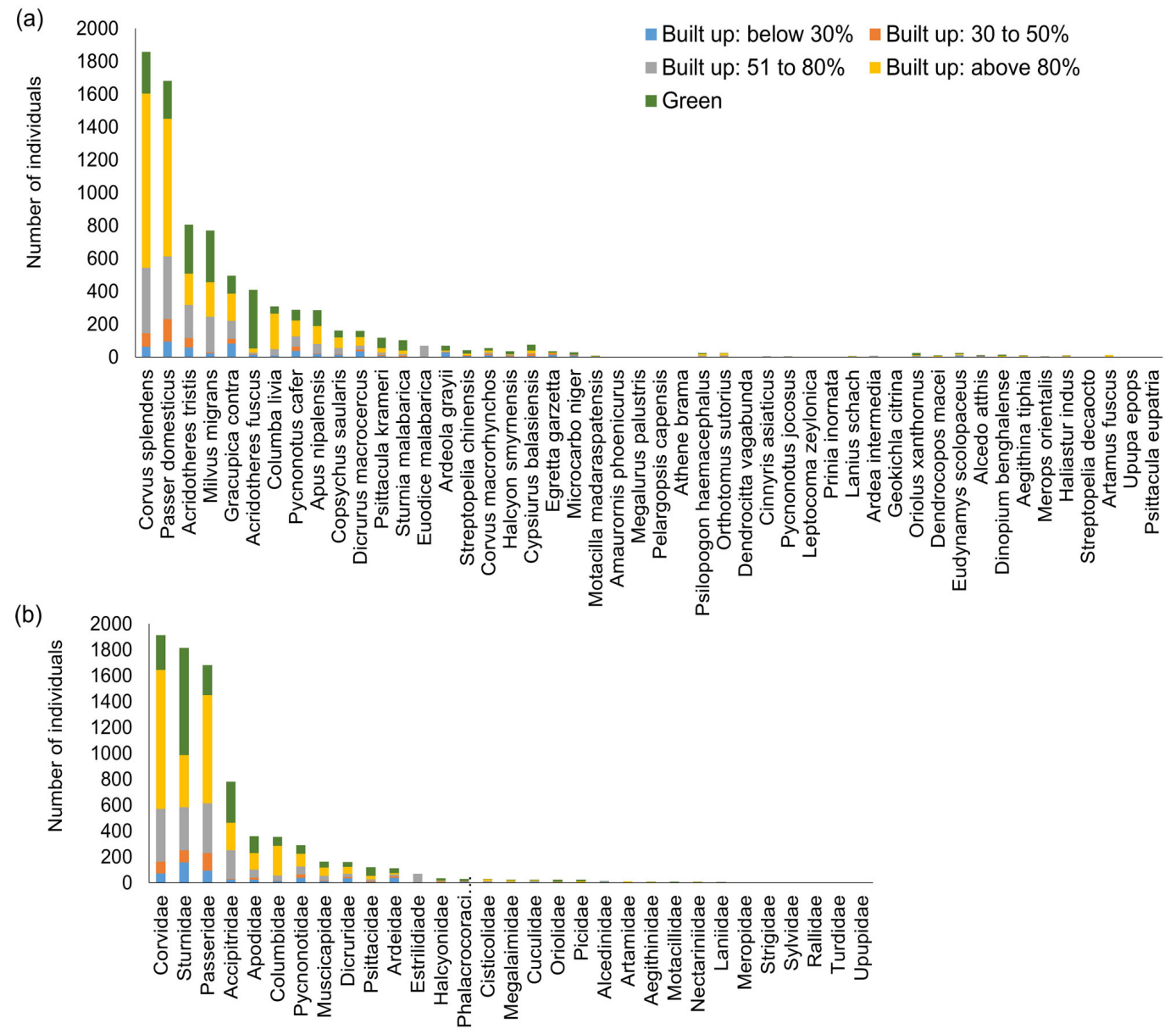

(c)

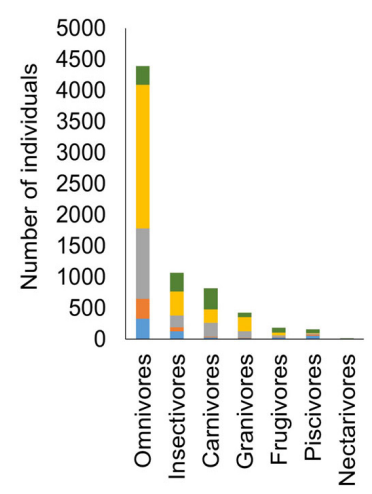

(d)

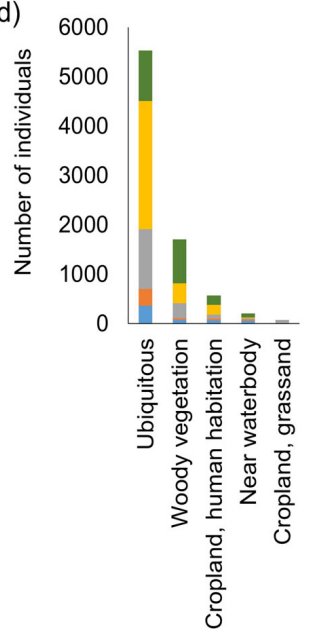


Fig. 4. A comparison of observed bird proportions (number of species and individuals) at different classes of built-up areas and at green areas. Four classes of built-up areas are presented based on the percentage of impervious surface at the survey point location: $0-30 \%, 31-50 \%, 51-80 \%$, and $80-100 \%$. Green area indicates locations within public/community parks, gardens, and sites with water bodies and vegetation. 4(a) and (b) show total bird proportions; (c) and (d) show bird proportions concerning their frequency of occurrences.

(a)

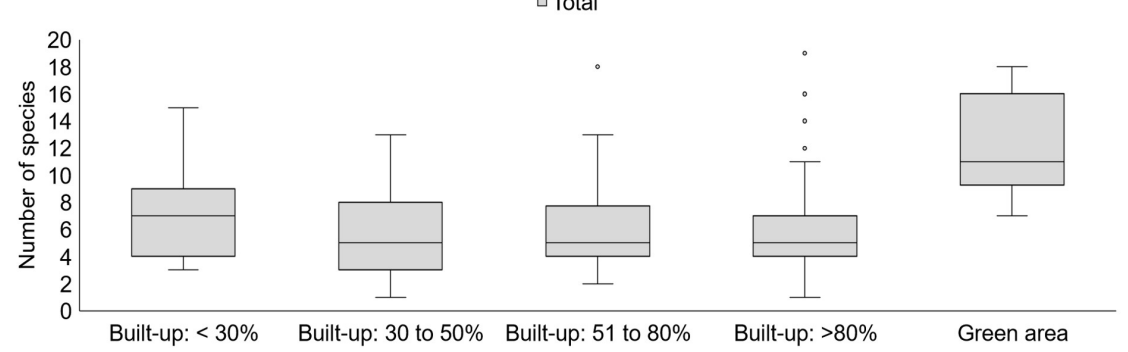

(b)

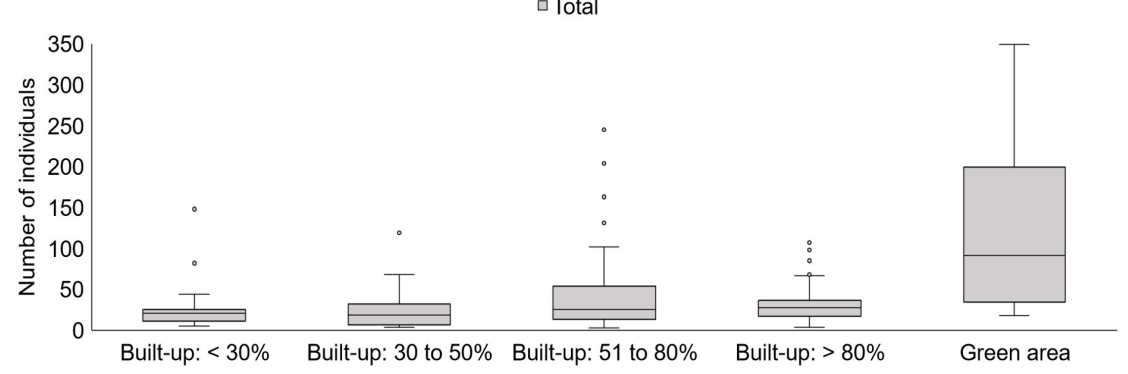

(c)

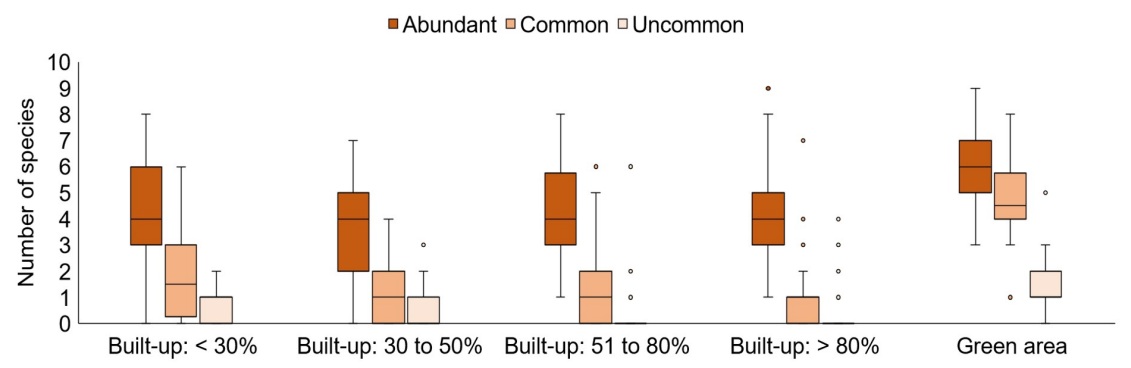

(d)

$\square$ Abundant $\square$ Common $\square$ Uncommon

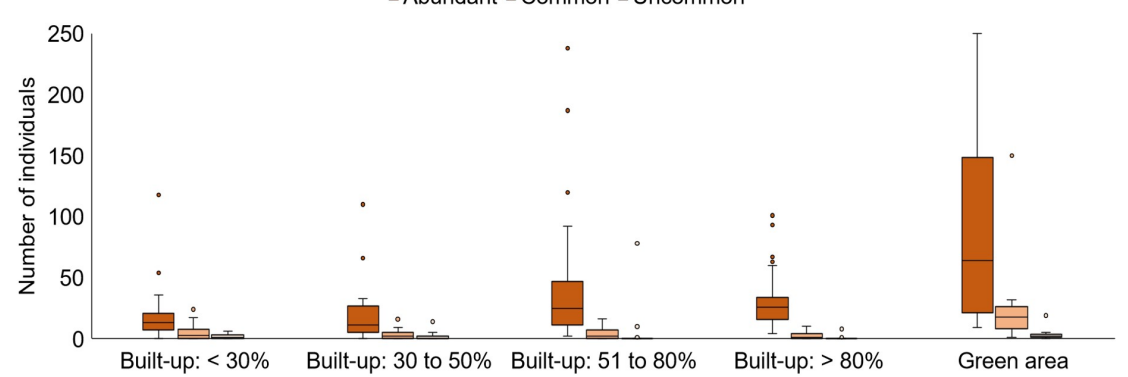


Table 2. Coefficient parameters of the individual variables in the selected top-ranked model (i.e., urban land cover effect model) of bird richness rate. Here, the response variable was $\log 10$ (bird richness rate). The $95 \%$ confidence intervals of the mean coefficient of the variables are presented in the table.

\begin{tabular}{|c|c|c|c|c|c|c|}
\hline & \multicolumn{2}{|c|}{$95 \%$ Confidence intervals } & \multirow[t]{2}{*}{ Estimate } & \multirow[t]{2}{*}{ Std.error } & \multirow[t]{2}{*}{$Z$ value } & \multirow[t]{2}{*}{$\operatorname{Pr}(>|z|)$} \\
\hline & $2.5 \%$ & $97.5 \%$ & & & & \\
\hline$\overline{\text { (Intercept) }}$ & 1.52 & 1.64 & 1.58 & 0.03 & 53.63 & $<2 \mathrm{e}-16 * * *$ \\
\hline Percentage of impervious surface & -0.15 & -0.02 & -0.09 & 0.03 & -2.73 & $0.007 * *$ \\
\hline Habitat Shannon metric & -0.03 & 0.11 & 0.04 & 0.034 & 1.13 & 0.26 \\
\hline Percentage of vegetation & -0.06 & 0.08 & 0.01 & 0.035 & 0.35 & 0.73 \\
\hline Distance to nearest parks & -0.10 & 0.03 & -0.04 & 0.031 & -1.11 & 0.27 \\
\hline Distance to nearest waterbody & -0.11 & 0.02 & -0.04 & 0.032 & -1.4 & 0.16 \\
\hline
\end{tabular}

Significance codes: $* * * P<0.001, * * P<0.01$

Fig. 5. Standard coefficients and associated $95 \%$ confidence interval in the selected causal path model (model b) of bird richness rate. The diagram shows relationships of the percentage of impervious surface (IS), habitat Shannon metric (HS), distance to nearest parks (DP), poverty index ratio (PI), human population (HP), and bird richness rate. Regular arrows highlight significant relationships and dashed arrows indicate non-significant relationships.

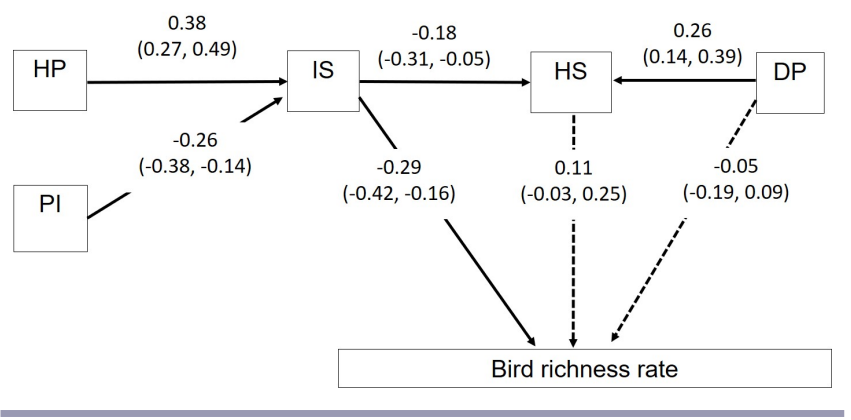

Fig. 6. Standard coefficients and associated $95 \%$ confidence interval in the selected causal path model (model a) of bird abundance rate. The diagram shows relationships of the percentage of impervious surface (IS), habitat Shannon metric (HS), distance to nearest parks (DP), poverty index ratio (PI), human population (HP), and bird richness rate. Regular arrows highlight significant relationships and the dashed arrow indicates non-significant relationships.

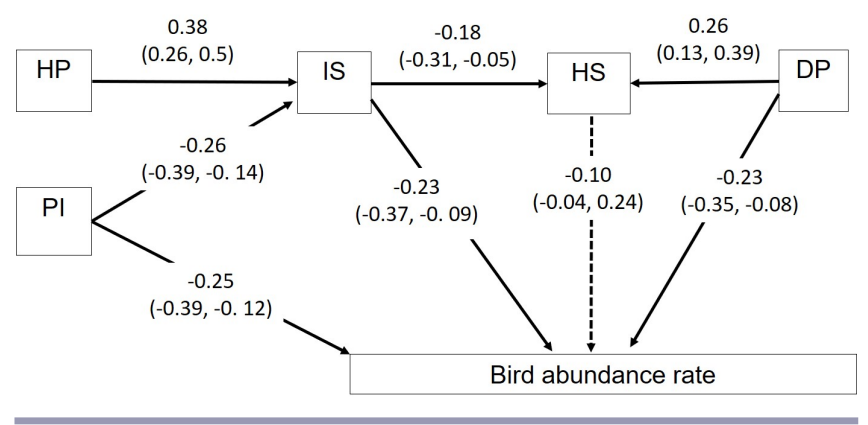

In the selected model coefficients summary for bird richness rate, the percentage of impervious surface was retained as the only significant variable $(P<0.01)$, confirming the negative influence of imperviousness on avian richness (Table 2; Appendix 3, Fig. A3.2). For bird abundance rate, habitat Shannon metric $(P<$ $0.05)$, distance to nearest parks $(P<0.01)$, and poverty index ratio $(P<0.01)$ were retained as significant variables (Table 3; Appendix 3, Fig. A3.3). This reveals the positive influence of habitat heterogeneity and the negative effect of distance to parks and poverty ratio on bird abundance rate. The explained variation in the selected model for the bird richness rate was $10 \%$ and, for the bird abundance rate, it was $13 \%$.

\section{Path analysis}

The path analysis of the hypothesized causal relationship of bird richness rate with selected variables showed that the models a and b were satisfactory based on $\chi^{2} P$ value $>0.05$, RMSEA $\leq 0.06$, and RMSEA $P$ values $>0.05$ (Table 4 ). We conducted a chi-square difference test in ANOVA and did not find any significant difference between the two models $(P=0.49)$, which indicated that the additional relationship path assumed in model a is ineffective. Thus, we selected model $\mathrm{b}$ as the best model because it also retained the lowest AIC value. It supported the hypothesis that there are indirect effects of poverty ratio (standardized coefficient $=0.08$ ) and human population (standardized coefficient $=-0.11$ ) on bird species richness mediated by impervious surface. However, the significance of the direct adverse effect of impervious surface (standardized coefficient $=-0.29$ ) was greater than the indirect effect of any socioeconomic factors (i.e., poverty ratio and human population) on bird richness rate (Fig. 5).

The path analysis of the hypothesized causal relationship of bird abundance rate with selected variables showed that only model a was satisfactory $\left(\chi^{2} P>0.05\right.$, RMSEA $\leq 0.06$, and RMSEA $P>$ 0.05; Table 4) and hereafter selected as the best model. It supported the hypothesis that the poverty ratio had both an indirect effect (standardized coefficient $=0.06$ ) mediated by impervious surface and a direct effect on bird abundance rate. Furthermore, human population also had an indirect effect (standardized coefficient $=-0.09$ ) on bird abundance rate, mediated by impervious surface. However, the significance of the direct adverse effect of poverty ratio (standardized coefficient $=-0.25$ ) was larger than the indirect effect of human population 
Table 3. Coefficient parameters of the individual variables in the top-ranked selected model (i.e., global model) of bird abundance rate. The response variable was $\log 10$ (bird abundance rate). The $95 \%$ confidence intervals of the mean coefficient of the variables are presented in the table.

\begin{tabular}{|c|c|c|c|c|c|c|}
\hline & \multicolumn{2}{|c|}{$95 \%$ Confidence intervals } & \multirow[t]{2}{*}{ Estimate } & \multirow[t]{2}{*}{ Std.error } & \multirow[t]{2}{*}{$Z$ value } & \multirow[t]{2}{*}{$\operatorname{Pr}(>|z|)$} \\
\hline & $2.5 \%$ & $97.5 \%$ & & & & \\
\hline (Intercept) & 3.09 & 3.28 & 3.19 & 0.05 & 65.03 & $<2 \mathrm{e}-16 * * *$ \\
\hline Percentage of impervious surface & -0.14 & 0.10 & -0.02 & 0.06 & -0.33 & 0.74 \\
\hline Habitat Shannon metric & 0.01 & 0.26 & 0.14 & 0.06 & 2.20 & $0.03 *$ \\
\hline Percentage of vegetation & -0.20 & 0.04 & -0.08 & 0.06 & -1.36 & 0.18 \\
\hline Distance to nearest parks & -0.27 & -0.06 & -0.16 & 0.05 & -3.00 & $0.003 * *$ \\
\hline Distance to nearest waterbody & -0.14 & 0.07 & -0.03 & 0.05 & -0.59 & 0.55 \\
\hline Human population & -0.16 & 0.08 & -0.04 & 0.06 & -0.69 & 0.49 \\
\hline Poverty index ratio & -0.26 & -0.04 & -0.15 & 0.05 & -2.72 & $0.007 * *$ \\
\hline Household income & -0.02 & 0.21 & 0.10 & 0.06 & 1.70 & 0.09 \\
\hline Higher education percentage & -0.03 & 0.19 & 0.08 & 0.06 & 1.44 & 0.15 \\
\hline
\end{tabular}

Significance codes: *** $P<0.001, * * P<0.01, * P<0.05, . P<0.10$

and the direct effect of any land cover variable (i.e., percentage of impervious surface and distance to nearest parks) on bird abundance rate (Fig. 6).

\section{DISCUSSION}

Our study provides the first evidence from a tropical megacity that local avian diversity within urban areas is driven by both habitat and humans. As hypothesized, land cover (i.e., level of imperviousness) and socioeconomic factors (i.e., poverty ratio) contributed to measures of bird diversity. It also supports our hypothesis that, although bird species diversity in Dhaka was favored by heterogeneous habitats in wealthy neighborhoods, bird communities remained largely composed of generalist species of low conservation concern, whereas specialist bird species were uncommon and rare.

\section{Bird diversity directly and indirectly affected by land cover and socioeconomic factors}

Our linear regression assessment of local bird species richness pointed to the well-known direct negative effect of urban land cover on biodiversity. Bird richness declined as imperviousness (i.e., human settlement and built-up extent) increased. Most earlier studies used the proportion of built-up areas (i.e., density/ percentage) to explore avian responses to the urban environment (Marzluff 2001). Several such existing studies reported a decline in species richness with increasing impervious surface (Tratalos et al. 2007, Gagné and Fahrig 2011, Silva et al. 2015, Carvajal-Castro et al. 2019). A similar adverse effect of increasing imperviousness on bird richness is evident in Dhaka. During the last two decades, a rapid shift in land cover features in this city has been noted by several studies (Sultana et al. 2009, Byomkesh et al. 2012, Jaman et al. 2020, Rahman and Szabó 2021). Because urbanization in Dhaka is messy, like in many other South Asian cities (Ellis and Roberts 2016), unplanned expansion has already resulted in a decline in the proportion of green spaces and water body areas (Appendix 4, Image A4.4; Sultana et al. 2009, Dewan et al. 2012). It is reported that only $8 \%$ of tree cover remains, and open areas are vanishing quickly within the city area (Byomkesh et al. 2012). A massive development very likely resulted in a reduction of heterogeneity in green habitat patches, which ultimately triggered a decline in avian diversity in urban areas with high imperviousness.

Our assessment of local bird species abundance suggested that the combined effects of urban land cover and socioeconomic factors are at play. More specifically, a decline in bird abundance was not only related to decreasing habitat heterogeneity and increasing distance from parks, but was also explained by a high poverty ratio in an urban neighborhood. Further, our extended path analysis, beyond the simplistic regression assessment, provided an in-depth understanding of the major factors driving urban birds. It indicated that the causal relationship paths between urban land cover, socioeconomic variables, and bird diversity is rather complex. We observed the greater significance of the direct negative effects of imperviousness on bird species richness and the poverty ratio on bird abundance (Figs. 5 and 6). Socioeconomic factors, namely poverty ratio and human population, appeared to indirectly affect both bird species richness and abundance; this effect was mediated by land cover, namely the proportion of impervious surface.

This may be because of the rapid development and land cover change together with a non-linear increase in urban poverty in the city (Calì 2009, Chen et al. 2016). Initially, increasing urbanization may improve poverty, but fast urbanization leads to greater poverty and inequality (Liddle 2017, UN-Habitat 2020). Such increasing poverty may eventually cause a decline in bird diversity in Asian tropical cities like Dhaka. Our observation, in turn, supports the concept of the so-called luxury effect on bird diversity, wherein wealthier urban neighborhoods contain more diverse bird populations (Kinzig et al. 2005, Melles 2005, Strohbach et al. 2009, Leong et al. 2018). In a wealthier community, individual choices and behaviors of property owners inadvertently improve resource availability for birds, such as food, water, and cover, which in turn may benefit urban birds (Nilon 2014). In poor neighborhoods (Appendix 4, Image A4.3), intensive human use of resources, high numbers of stray dogs and cats, and possibly active exploitation and persecution of birds 
Table 4. A comparison of the path models fit to explain variation in resident bird richness rate and abundance rate in relation to selected urban land cover and socioeconomic variables in Dhaka city.

\begin{tabular}{|c|c|c|c|c|c|c|c|c|c|c|c|c|}
\hline \multirow[b]{2}{*}{ Model } & \multicolumn{6}{|c|}{ Bird richness rate } & \multicolumn{6}{|c|}{ Bird abundance rate } \\
\hline & $x^{2}$ & $\mathrm{df}$ & $\begin{array}{c}\chi^{2} \\
P \text { value }\end{array}$ & RMSEA & $\begin{array}{c}\text { RMSEA } \\
P \text { value }\end{array}$ & AIC & $\chi^{2}$ & $\mathrm{df}$ & $\begin{array}{c}\chi^{2} \\
P \text { value }\end{array}$ & RMSEA & $\begin{array}{c}\text { RMSEA } \\
P \text { value } \\
\end{array}$ & AIC \\
\hline Model a & 3.73 & 4 & 0.443 & 0.00 & 0.656 & 1861.36 & 4.49 & 4 & 0.343 & 0.03 & 0.565 & 2797.86 \\
\hline Model b & 4.20 & 5 & 0.521 & 0.00 & 0.741 & 1859.83 & 16.19 & 5 & 0.006 & 0.11 & 0.044 & 2807.56 \\
\hline Model c & 19.61 & 5 & 0.001 & 0.12 & 0.016 & 1875.24 & 20.37 & 5 & 0.001 & 0.13 & 0.012 & 2811.73 \\
\hline Model d & 35.31 & 7 & 0.000 & 0.15 & 0.001 & 2417.55 & 47.31 & 7 & 0 & 0.17 & 0 & 3365.28 \\
\hline Model e & 29.69 & 7 & 0.000 & 0.13 & 0.003 & 1887.27 & 27.89 & 7 & 0 & 0.13 & 0.006 & 2821.21 \\
\hline
\end{tabular}

may directly negatively impact bird abundance patterns. Our data were unable to assess the causes underlying the observed effect of socioeconomic status on bird diversity. Therefore, further studies into the human dimensions of urban bird diversity patterns would be useful for conservation management in tropical cities like Dhaka.

\section{Dhaka bird community dominated by generalists}

Although bird species diversity in Dhaka was favored by heterogeneous habitats in wealthy neighborhoods, bird communities largely comprised generalist species of low conservation concern, whereas specialist bird species were uncommon or rare. Generalist species of the omnivore feeding guild and with ubiquitous habitat preferences were the most abundant in Dhaka city. Birds from other feeding guilds (i.e., frugivore and nectarivore) and with special habitat preferences (i. e., near water bodies, cultivated land, and grassland) became less common with increasing urbanization. Such variability in the occurrence of birds from different guilds has been reported earlier not only in many temperate cities (Allen and O'Connor 2000, Lindsay et al. 2002) but also in tropical Asian cities (e.g., Singapore and Kolkata; Lim and Sodhi 2004, Sengupta et al. 2014, Katuwal et al. 2018).

Omnivores, such as Corvus splendens, Passer domesticus, Acridotheres tristis, and Gracupica contra, thrive on rubbish and gather around landfills (IUCN Bangladesh 2015); thus, the presence of scattered waste dumping sites (Appendix 4, Image A4.2) may favor the high abundance of omnivorous birds in Dhaka, as is the case with waste disposal sites in other South Asian cities (e.g., Kathmandu; Dahal and Bhuju 2008).

Along with the availability of anthropogenic food sources, behavioral innovation can contribute to the successful exploitation of urban habitats (Mennechez and Clergeau 2006). One example is the Milvus migrans, abundant in Dhaka city, which feeds on decaying animals from waste disposal sites and builds nests on tall transmission towers and telephone lines (IUCN Bangladesh 2015; Appendix 4, Image A4.1). Further, in cities, birds may better escape predators and hunting pressure and sustain healthy populations. For example, a widespread common resident, Columba livia, is subject to illegal hunting in the countryside but not within Dhaka city. Thus, the population is sustained by its adaptation to urban life (IUCN Bangladesh 2015).
In general, bird species richness and abundance are highest in green sites in Dhaka. Within the central urban area of the city, avian diversity is concentrated in the remnant old and extensive green sites such as the Ramna Park and the national botanical garden (Islam et al. 2014, Rajia et al. 2015). Additionally, many infrequent/rare resident birds (e.g., Pycnonotus jocosus) may exploit urban areas without successfully breeding in the city. The presence of such birds in urban areas is possibly sustained by suburban and rural areas adjacent to the city such as suburban areas of Keraniganj to the southwest.

\section{INSIGHTS AND FUTURE RESEARCH}

Our paper provides essential insights on bird species richness and abundance (as a proxy for overall biodiversity) and their main drivers in Dhaka city. We found that both land cover (namely imperviousness) and socioeconomic (namely poverty) factors are playing a major role in shaping bird diversity patterns. Our study, however, may lack a full picture of avian species composition across the city because it was based on a single season of bird surveys. Further, our assessment of bird occurrences and their affinity to urban gradients was based on simple explorative analyses. Nevertheless, this kind of investigation is a significant first step in any city lacking previous urban biodiversity research (Marzluff 2001). A general understanding of how urbanizationrelated factors affect different components of biodiversity is still lacking for tropical megacities. We emphasize that multiple years of surveys should be carried out to monitor and explain bird diversity patterns along a gradient of urbanization in cities like Dhaka. Future studies should consider advanced assessment approaches (Callaghan et al. 2019) to understand species-specific adaptations of birds, as well as trends of community homogenization (Morelli et al. 2016) across urban areas, and thereby support the foundation for urban biodiversity planning in tropical megacities. The preservation of urban birds and other components of biodiversity, for the benefit of human well-being, should be one of the major goals during any urban development process in a well-planned city.

Responses to this article can be read online at: https://www.ecologyandsociety.org/issues/responses. php/12905 


\section{Author Contributions:}

All authors were involved in the study design. MS, MNN, and $M U$ contributed through data collection. MS conducted the analysis and wrote the manuscript. IS contributed during the writing and revising of the manuscript.

\section{Acknowledgments:}

We acknowledge the support of all the students of the University of Dhaka, Jagannath University, and local ornithologists who assisted during the field survey in Dhaka. We thank A.B. M. Sarwar Alam and Mohsin Kobir Miron for cross-checking and corrections in the bird checklist. We also thank Luca Corlatti for his assistance with statistics and Ottavio Jani for the English proofreading of the final manuscript. MS was supported by LGFG (Landesgraduiertenförderungsgesetz) funding from the International Graduate Academy (IGA) of the University of Freiburg. The article processing charge was funded by the Baden-Wuerttemberg Ministry of Science, Research and Art and the University of Freiburg in the funding programme Open Access Publishing.

\section{Data Availability:}

The bird data that support the findings of this paper are available in the electronic supplementary materials. Further data and statistical analysis can be found at this link: https:/losf.iolhy 784l? view only $=2893$ ed3ac3 db49c789698975e9ff6682

\section{LITERATURE CITED}

Ahamed, S., and Md. M. Hasan. 2010. Planned development for urban growth management: a case study on two wards of Dhaka city. Journal of Bangladesh Institute of Planners 3:113-127. https://www.bip.org.bd/admin/uploads/bip-publication/publication-3/ paper/20130722135205.pdf

Akinwande, M. O., H. G. Dikko, and A. Samson. 2015. Variance inflation factor: as a condition for the inclusion of suppressor variable(s) in regression analysis. Open Journal of Statistics 5:754-767. https://doi.org/10.4236/ojs.2015.57075

Allen, A. P., and R. J. O'Connor. 2000. Hierarchical correlates of bird assemblage structure on northeastern U.S.A. lakes. Environmental Monitoring and Assessment 62:15-37. https://doi. org/10.1023/A:1006244932033

Aronson, M. F., F. A. La Sorte, C. H. Nilon, M. Katti, M. A. Goddard, C. A. Lepczyk, P. S. Warren, N. S. G. Williams, S. Cilliers, B. Clarkson, and C. Dobbs, et al. 2014. A global analysis of the impacts of urbanization on bird and plant diversity reveals key anthropogenic drivers. Proceedings of the Royal Society B: Biological Sciences 281:20133330. https://doi.org/10.1098/ $\underline{\text { rspb.2013.3330 }}$

Banu, F. A., M. Akash, G. W. Chowdhury, and M. A. Hossain. 2016. Status and seasonal occurrence of birds in Dhaka University campus. Dhaka University Journal of Biological Sciences 25(1):27-37. https://doi.org/10.3329/dujbs.v25i1.28492

Bartoń, K. 2020. MuMIn: multi-model inference, R package version 1.43.17. [online] URL: https://cran.r-project.org/web/ packages/MuMIn/MuMIn.pdf
Bibby, C. J., N. D. Burgess, D. A. Hill, and S. H. Mustoe. 2000. Bird census techniques. Academic Press, London, UK.

Blair, R. B. 2001. Birds and butterflies along urban gradients in two ecoregions of the United States: is urbanization creating a homogeneous fauna? Pages 33-56 in J. L. Lockwood, and M. L. McKinney, editors. Biotic homogenization. Kluwer Academic, New York, New York, USA. https://doi.org/10.1007/978-1-4615-1261-5_3

Byomkesh, T., N. Nakagoshi, and A. M. Dewan. 2012. Urbanization and green space dynamics in Greater Dhaka, Bangladesh. Landscape and Ecological Engineering 8:45-58. https://doi.org/10.1007/s11355-010-0147-7

Calì, M. 2009. Urbanization, inequality and economic growth: evidence from Indian states. World Bank, Washington, D.C., USA. [online] URL: https://openknowledge.worldbank.org/ handle/10986/9248

Callaghan, C. T., R. E. Major, J. H. Wilshire, J. M. Martin, R. T. Kingsford, and W. K. Cornwell. 2019. Generalists are the most urban-tolerant of birds: a phylogenetically controlled analysis of ecological and life history traits using a novel continuous measure of bird responses to urbanization. Oikos 128(6):845-858. https:// doi.org/10.1111/oik.06158

Carvajal-Castro, J. D., A. M. Ospina-L, Y. Toro-López, A. PulidoG, L. X. Cabrera-Casas, S. Guerrero-Peláez, V. H. GarciaMerchán, and F. Vargas-Salinas. 2019. Birds vs bricks: patterns of species diversity in response to urbanization in a Neotropical Andean city. PLoS ONE 14(6):e0218775. https://doi.org/10.1371/ journal.pone.0218775

Chace, J. F., and J. J. Walsh. 2006. Urban effects on native avifauna: a review. Landscape and Urban Planning 74(1):46-69. https://doi.org/10.1016/j.landurbplan.2004.08.007

Chen, G., A. K. Glasmeier, M. Zhang, and Y. Shao. 2016. Urbanization and income inequality in post-reform China: a causal analysis based on time series data. PLoS ONE 11(7): e0158826. https://doi.org/10.1371/journal.pone.0158826

Colwell, R.K. 2009. Biodiversity: concepts, patterns, and measurement. Pages 257-263 in S. A. Levin, S. R. Carpenter, H. C. J. Godfray, A. P. Kinzig, M. Loreau, J. B. Losos, B. Walker, and D. S. Wilcove, editors. The Princeton guide to ecology. Princeton University Press, Princeton, New Jersey, USA. https:// doi.org/10.1515/9781400833023.257

Dahal, B. R., and D. R. Bhuju. 2008. Bird mobility and their habitat at Tribhuvan International Airport, Kathmandu. Nepal Journal of Science and Technology 9:119-130. https://doi. org/10.3126/njst.v9i0.3175

Dewan, A., G. Kiselev, D. Botje, G. I. Mahmud, Md. H. Bhuian, and Q. K. Hassan. 2021. Surface urban heat island intensity in five major cities of Bangladesh: patterns, drivers and trends. Sustainable Cities and Society 71:102926. https://doi.org/10.1016/ j.scs.2021.102926

Dewan, A. M., Y. Yamaguchi, and Md. Z. Rahman. 2012. Dynamics of land use/cover changes and the analysis of landscape fragmentation in Dhaka metropolitan, Bangladesh. GeoJournal 77:315-330. https://doi.org/10.1007/s10708-010-9399-x 
Dormann, C. F., J. Elith, S. Bacher, C. Buchmann, G. Carl, G. Carré, J. R. G. Marquéz, B. Gruber, B. Lafourcade, P. J. Leitão, et al. 2013. Collinearity: a review of methods to deal with it and a simulation study evaluating their performance. Ecography 36 (1):27-46. https://doi.org/10.1111/j.1600-0587.2012.07348.x

Ellis, P., and M. Roberts. 2016. Leveraging urbanization in South Asia: managing spatial transformation for prosperity and livability. World Bank, Washington, D.C., USA. [online] URL: https:/elibrary.worldbank.org/doi/abs/10.1596/978-1-4648-0662-9

Evans, K. L., J. J. D. Greenwood, and K. J. Gaston. 2007. The positive correlation between avian species richness and human population density in Britain is not attributable to sampling bias. Global Ecology and Biogeography 16(3):300-304. https://doi. org/10.1111/j.1466-8238.2006.00288.x

Evans, K. L., S. E. Newson, and K. J. Gaston. 2009. Habitat influences on urban avian assemblages. Ibis 151:19-39. https:// doi.org/10.1111/j.1474-919X.2008.00898.X

Faeth, S. H., C. Bang, and S. Saari. 2011. Urban biodiversity: patterns and mechanisms. Annals of the New York Academy of Sciences 1223:69-81. https://doi.org/10.1111/j.1749-6632.2010.05925. $\underline{\mathrm{x}}$

Gagné, S., and L. Fahrig. 2011. Do birds and beetles show similar responses to urbanization? Ecological Applications 21:2297-2312. https://doi.org/10.1890/09-1905.1

Garaffa, P. I., J. Filloy, and M. I. Bellocq. 2009. Bird community responses along urban-rural gradients: does the size of the urbanized area matter? Landscape and Urban Planning 90:33-41. https://doi.org/10.1016/j.landurbplan.2008.10.004

Gotelli, N. J., and A. M. Ellison. 2013. A primer of ecological statistics. Second edition. Sinauer Associates, Sunderland, Massachusetts, USA.

Gregory, R. D., D. W. Gibbons, and P. F. Donald. 2004. Bird census and survey techniques. Pages 17-56 in W. J. Sutherland, I. Newton, R. Green, editors. Bird ecology and conservation: a handbook of techniques. Oxford University Press, New York, New York, USA. https://doi.org/10.1093/acprof: oso/9780198520863.003.0002

Grimm, N. B., S. H. Faeth, N. E. Golubiewski, C. L. Redman, J. Wu, X. Bai, and J. M. Briggs. 2008. Global change and the ecology of cities. Science 319(5864):756-760. https://doi.org/10.1126/ science. 1150195

Hu, L., and P. M. Bentler. 1999. Cutoff criteria for fit indexes in covariance structure analysis: conventional criteria versus new alternatives. Structural Equation Modeling: A Multidisciplinary Journal 6(1):1-55. https://doi.org/10.1080/10705519909540118

International Union for Conservation of Nature (IUCN) Bangladesh. 2015. Red List of Bangladesh: volume 3: birds. IUCN, Dhaka, Bangladesh.

Islam, M. S., O. Shahadat, M. M. Kabir, M. A. Rashid, H. A. Razi, M. Kamruzzaman, S. M. I. Alam, T. Mustafa, and M. S. Islam. 2014. Avifauna of the National Botanical Garden of Bangladesh. Journal of Taxonomy and Biodiversity Research 6:17-20.
Jaman, S., X. Zhang, and F. Islam. 2020. Carbon storage and tree diversity in the urban vegetation of Dhaka city, Bangladesh: a study based on intensive field investigation. Arboricultural Journal 42(2):76-92. https://doi.org/10.1080/03071375.2020.1755186

Katuwal, H. B., N. M. B. Pradhan, J. J. Thakuri, K. P. Bhusal, P. C. Aryal, and I. Thapa. 2018. Effect of urbanization and seasonality in bird communities of Kathmandu Valley, Nepal. Proceedings of the Zoological Society 71:103-113. https://doi. org/10.1007/s12595-018-0265-Z

Kendal, D., N. S. G. Williams, and K. J. H. Williams. 2012. Drivers of diversity and tree cover in gardens, parks and streetscapes in an Australian city. Urban Forestry and Urban Greening 11:257-265. https://doi.org/10.1016/j.ufug.2012.03.005

Khaleda, S., Q. A. Mowla, and Y. Murayama. 2017. Dhaka Metropolitan Area. Pages 195-215 in Y. Murayama Y, C. Kamusoko, A. Yamashita, R. Estoque, editors. Urban development in Asia and Africa. Springer, Singapore.

Kinzig, A. P., P. Warren, C. Martin, D. Hope, and M. Katti. 2005. The effects of human socioeconomic status and cultural characteristics on urban patterns of biodiversity. Ecology and Society 10(1):23. https://doi.org/10.5751/ES-01264-100123

Leong, M., R. R. Dunn, and M. D. Trautwein. 2018. Biodiversity and socioeconomics in the city: a review of the luxury effect. Biology Letter 14:20180082. http://dx.doi.org/10.1098/rsbl.2018.0082

Liddle, B. 2017. Urbanization and inequality/poverty. Urban Science 1(4):35. https://doi.org/10.3390/urbansci1040035

Lim, H. C., and N. S. Sodhi. 2004. Responses of avian guilds to urbanisation in a tropical city. Landscape and Urban Planning 66:199-215. https://doi.org/10.1016/S0169-2046(03)00111-7

Lindsay, A. R., S. S. Gillum, and M. W. Meyer. 2002. Influence of lakeshore development on breeding bird communities in a mixed northern forest. Biological Conservation 107:1-11. https:// doi.org/10.1016/S0006-3207(01)00260-9

Loss, S. R., M. O. Ruiz, and J. D. Brawn. 2009. Relationships between avian diversity, neighborhood age, income, and environmental characteristics of an urban landscape. Biological Conservation 142:2578-2585. https://doi.org/10.1016/j.biocon.2009.06.004

Luck, G. W., and L. T. Smallbone. 2010. Species diversity and urbanisation: patterns, drivers and implications. Pages 88-119 in K. J. Gaston, editor. Urban ecology. Cambridge University Press, Cambridge, UK. https://doi.org/10.1017/CBO9780511778483.006

Manfredo, M. J. 2008. Who cares about wildlife? Social science concepts for exploring human-wildlife relationships and conservation issues. Springer, New York, New York, USA.

Marzluff, J. M. 2001. Worldwide urbanization and its effects on birds. Pages 19-47 in J. M. Marzluff, R. Bowmann and R. Donnelly, editors. Avian ecology and conservation in an urbanizing world. Springer, New York, New York, USA. https:// doi.org/10.1007/978-1-4615-1531-9 2

Marzluff, J. M. 2005. Island biogeography for an urbanizing world: how extinction and colonization may determine biological 
diversity in human-dominated landscapes. Urban Ecosystems 8:157-177. https://doi.org/10.1007/s11252-005-4378-6

McKinney, M. L. 2002. Urbanization, biodiversity and conservation: the impacts of urbanization on native species are poorly studied, but educating a highly urbanized human population about these impacts can greatly improve species conservation in all ecosystems. BioScience 52:883-890 https://doi. org/10.1641/0006-3568(2002)052[0883:UBAC]2.0.CO;2

McKinney, M. L. 2008. Effects of urbanization on species richness: a review of plants and animals. Urban Ecosystems 11:161-176. https://doi.org/10.1007/s11252-007-0045-4

Meléndez-Ackerman, E. J., R. Santiago-Bartolomei, C. P. VilaRuiz, L. E. Santiago, D. García-Montiel, J. C. Verdejo-Ortiz, H. Manrique-Hernández, and E. Hernández-Calo. 2014. Socioeconomic drivers of yard sustainable practices in a tropical city. Ecology and Society 19(3):20. http://dx.doi.org/10.5751/ES-06563-190320

Melles, S. J. 2005. Urban bird diversity as an indicator of human social diversity and economic inequality in Vancouver, British Columbia. Urban Habitats 3(1):25-48. [online] URL: https:// www.urbanhabitats.org/v03n01/vancouver pdf.pdf

Mennechez, G., and P. Clergeau. 2006. Effect of urbanisation on habitat generalists: starlings not so flexible? Acta Oecologica 30 (2):182-191. https://doi.org/10.1016/j.actao.2006.03.002

Morelli, F., Y. Benedetti, J. D. Ibáñez-Álamo, J. Jokimäki, R. Mänd, P. Tryjanowski, and A. P. Møller. 2016. Evidence of evolutionary homogenization of bird communities in urban environments across Europe. Global Ecology and Biogeography 25(11):1284-1293. https://doi.org/10.1111/geb.12486

Muller, N., P. Werner, and J. G. Kelcey. 2010. Urban biodiversity and design. Wiley-Blackwell, Hoboken, New Jersey, USA. https:// doi.org/10.1002/9781444318654

Nilon, C. 2014. The urban system: social drivers. Pages 91-101 in R. A. McCleery, C. E. Moorman, and M. N. Peterson, editors. Urban wildlife conservation: theory and practice. Springer, New York, New York, USA. https://doi.org/10.1007/978-1-4899-7500-3 _6

Oksanen, J., F. G. Blanchet, R. Kindt, P. Legendre, P. R. Minchin, R. B. O'hara, G. L. Simpson, P. Solymos, M. H. H. Stevens, and H. Wagner. 2011. vegan: Community Ecology Package. R package version 1.17-10.

Peterson, B. G., P. Carl, K. Boudt, R. Bennett, J. Ulrich, E. Zivot, D. Cornilly, E. Hung, M. Lestel, K. Balkissoon, and D. Wuertz. 2018. Package 'PerformanceAnalytics'. R Team Cooperation.

R Core Team. 2019. R: A language and environment for statistical computing. R Foundation for Statistical Computing, Vienna, Austria. [online] URL: https://www.R-project.org/

Rahman, Md. M., and G. Szabó. 2021. Impact of land use and land cover changes on urban ecosystem service value in Dhaka, Bangladesh. Land 10(8):793. https://doi.org/10.3390/land10080793

Rajia, S., M. M. Alam, G. W. Chowdhury, M. Akash, and M. A. Islam. 2015. Status and diversity of birds of Ramna Park, Dhaka, Bangladesh. Bangladesh Journal of Zoology 43(2):291-301. https://doi.org/10.3329/bjz.v43i2.27399
RAJUK. 2015. Dhaka structure plan, 2016 - 2035, Dhaka. [online] URL: https://rajuk.portal.gov.bd/sites/default/files/files/ rajuk.portal.gov.bd/page/0a05e9d0 $03 \mathrm{f} 7 \quad 48 \mathrm{e} 4$ bfd5 cad5fbcd5e23/2021-06-22-08-35-c8b98a96d0cadc8d87fa1c61f56966bb.pdf

Rodewald, A. D., and S. D. Gehrt. 2014. Wildlife population dynamics in urban landscapes. Pages $117-148$ in R. A. McCleery, C. E. Moorman, M. N. Peterson, editors. Urban wildlife conservation, theory and practice. Springer, New York, New York, USA. https://doi.org/10.1007/978-1-4899-7500-3 8

Rosseel, Y. 2012. lavaan: an R package for structural equation modeling. Journal of Statistical Software 48:1-36. https://doi. org/10.18637/jss.v048.i02

RStudio Team. 2019. RStudio: integrated development for R. RStudio Inc., Boston, Massachusetts, USA.

Sarker, N. J., D. Sultana, M. F. Jaman, and M. K. Rahman. 2009. Diversity and population of avifauna of two urban sites in Dhaka, Bangladesh. Ecoprint: An International Journal of Ecology 16:1-7. https://doi.org/10.3126/eco.v16i0.3464

Sengupta, S., M. Mondal, and P. Basu, 2014. Bird species assemblages across a rural urban gradient around Kolkata, India. Urban Ecosystems 17:585-596. https://doi.org/10.1007/s11252-013-0335y

Shovon, S. C., M. S. Islam, M. Jubayer-Al-Mahmud, S. N. Chowdhury, M. Nazmul, T. S. Alam, and M. M. Islam. 2014. Diversity of avifauna in Sher-E-Bangla Agricultural University campus. International Journal of Business, Social and Scientific Research 2(1):58-63 [online] URL: http://www.ijbssr.com/ journal/details/diversity-of-avifauna-in-sher-e-bangla-agriculturaluniversity-campus-14013048

Silva, C. P., C. E. García, S. A. Estay, O. Barbosa, and M. G. Chapman. 2015. Bird richness and abundance in response to urban form in a Latin American city: Valdivia, Chile as a case study. PLoS ONE 10(9):e0138120. https://doi.org/10.1371/ journal.pone. 0138120

Strohbach, M. W., D. Haase, and N. Kabisch. 2009. Birds and the city: urban biodiversity, land use, and socioeconomics. Ecology and Society 14(2): 31. https://doi.org/10.5751/ES-03141-140231

Sultana, M., L. Corlatti, and I. Storch. 2021. The interaction of imperviousness and heterogeneity drives bird richness patterns in South Asian cities. Urban Ecosystem 24:335-344. https://doi. org/10.1007/s11252-020-01037-8

Sultana, M. S., G. M. T. Islam, and Z. Islam. 2009. Pre- and posturban wetland area in Dhaka city, Bangladesh: a remote sensing and GIS analysis. Journal of Water Resource and Protection 1 (6):414-421. https://doi.org/10.4236/jwarp.2009.16050

Tomer, A., and B. H. Pugesek. 2003. Guidelines for the implementation and publication of structural equation models. Pages 125-140 in B. H. Pugesek, A. Tomer, and A. von Eye, editors. Structural equation modeling: applications in ecological and evolutionary biology. Cambridge University Press, Cambridge, UK. https://doi.org/10.1017/CBO9780511542138.006

Tratalos, J., R. A. Fuller, K. L. Evans, R. G. Davies, S. E. Newson, J. J. D. Greenwood, and K. J. Gaston. 2007. Bird densities are associated with household densities. Global Change Biology 13:1685-1695. https://doi.org/10.1111/j.1365-2486.2007.01390.x 
Uddin, Md. J., and Y. K. Jeong. 2021. Urban river pollution in Bangladesh during last 40 years: potential public health and ecological risk, present policy, and future prospects toward smart water management. Heliyon 7(2):e06107. https://doi.org/10.1016/ j.heliyon.2021.e06107

United Nations (UN), Department of Economic and Social Affairs, Population Division. 2014. World urbanization prospects, the 2014 revision: highlights. United Nations, New York, New York, USA. https://doi.org/10.18356/527e5125-en

UN-Habitat. 2020. World cities report 2020: the value of sustainable urbanization. United Nations Human Settlements Programme, Nairobi, Kenya. [online] URL: https://unhabitat. org/sites/default/files/2020/10/wcr_2020_report.pdf

Venables, W. N., and B. D. Ripley. 2002. Modern applied statistics with S. Fourth edition. Springer, New York, New York, USA. https://doi.org/10.1007/978-0-387-21706-2

Verma S. K., and T. D. Murmu. 2015. Impact of environmental and disturbance variables on avian community structure along a gradient of urbanization in Jamshedpur, India. PLoS ONE 10(7): e0133383. https://doi.org/10.1371/journal.pone.0133383

Wright, S. 1934. The method of path coefficients. Annals of Mathematics and Statistics 5:161-215. https://doi.org/10.1214/ aoms/1177732676

Zinia, N. J., and P. McShane. 2018. Ecosystem services management: an evaluation of green adaptations for urban development in Dhaka, Bangladesh. Landscape and Urban Planning 173:23-32. https://doi.org/10.1016/j.landurbplan.2018.01.008

Zuur, A. F., J. M. Hilbe, and E. N. Ieno. 2013. A beginner's guide to GLM and GLMM with R: a frequentist and Bayesian perspective for ecologists. Highland Statistics, Newburgh, UK. 


\title{
Appendix 1
}

\author{
METHODS
}

\section{Bird diversity}

In addition to our major assessment (i.e., presented in the paper), we initially inspected the pattern in relative abundance of each species at an increasing level of urbanization (i.e., based on proportion of built-up areas). Several conventional concepts regarding the response of wildlife species to urban gradient is available (Blair 1996, Rodewald and Gehrt 2014, Fischer et al. 2015). Here, we followed such conceptual understanding to visualize urban affinity of each birds at three levels: (i) urban dependents with peaked relative abundance in highly built-up areas (i.e., areas containing impervious surface $>80 \%$ ); (ii) urban exploiters, which are abundant/common species with high relative abundance at a suburban/intermediate level of built-up areas (i.e., areas containing impervious surface between $>30 \%$ and $<80 \%$ ) and in urban green areas; (iii) urban tolerant birds, which are uncommon/infrequent species across urban areas, and are abundant/common species with peaked relative abundance only in lightly urbanized areas (i.e., areas containing impervious surface $<30 \%$ ) and at urban green areas. 
Table A1.1 Variables and sources

\begin{tabular}{|c|c|c|}
\hline Variables & Description & Source \\
\hline $\begin{array}{l}\text { Percentage of } \\
\text { impervious surface }\end{array}$ & $\begin{array}{l}\text { Value 0-100, Percentage of 'Impervious } \\
\text { surface' from 'Global Man-made } \\
\text { Impervious Surface (GMIS) and Global } \\
\text { Human Built-up and Settlement Extent } \\
\text { (HBASE) data products', spatial resolution } \\
\sim 30 \mathrm{~m} \text {. }\end{array}$ & $\begin{array}{l}\text { Brown de Colstoun } \\
\text { et al. } 2017\end{array}$ \\
\hline $\begin{array}{l}\text { Habitat Shannon } \\
\text { metric }\end{array}$ & $\begin{array}{l}\text { Value of 'Diversity of EVI (Enhanced } \\
\text { Vegetation Index)', from Global Habitat } \\
\text { Heterogeneity dataset, spatial resolution } \\
30 \text { arc-second. }\end{array}$ & $\begin{array}{l}\text { Tuanmu and Jetz } \\
2015\end{array}$ \\
\hline $\begin{array}{l}\text { Distance to the nearest } \\
\text { park }\end{array}$ & $\begin{array}{l}\text { Distance }(\mathrm{m}) \text { from grid cell centroids to the } \\
\text { nearest edge of park. Value is estimated } \\
\text { using ArcGIS tools. }\end{array}$ & $\begin{array}{l}\text { OpenStreetMap } \\
\text { contributors } 2018\end{array}$ \\
\hline $\begin{array}{l}\text { Distance to the nearest } \\
\text { waterbody }\end{array}$ & $\begin{array}{l}\text { Distance }(\mathrm{m}) \text { from grid cell centroids to the } \\
\text { nearest edge of waterbody. Value is } \\
\text { estimated using ArcGIS tools. }\end{array}$ & $\begin{array}{l}\text { OpenStreetMap } \\
\text { contributors } 2018\end{array}$ \\
\hline $\begin{array}{l}\text { Percentage of } \\
\text { vegetation }\end{array}$ & $\begin{array}{l}\text { Value from 'Average maximum green } \\
\text { vegetation fraction, MODIS- maximum } \\
\text { green vegetation fraction, based on } 12 \\
\text { years (2001-2012), spatial resolution } \\
\sim 1 \mathrm{Km} .\end{array}$ & Broxton et al. 2014 \\
\hline Human population & $\begin{array}{l}\text { Value of estimated number of people per } \\
\text { grid square, Spatial resolution } \\
\sim 0.000833333 \text { decimal degrees (approx } \\
100 \text { m at the equator). }\end{array}$ & WorldPop 2017 \\
\hline Poverty index ratio & $\begin{array}{l}\text { Estimates of mean likelihood of living in } \\
\text { poverty per grid square, as defined by } \\
\$ 2.50 \text { a day poverty line, spatial resolution } \\
\sim 0.00833333 \text { decimal degrees (approx. } \\
1 \mathrm{~km} \text { at the equator). }\end{array}$ & Steele et al. 2017 \\
\hline Household income & $\begin{array}{l}\text { Estimates of mean household income in } \\
\text { USD per grid square. spatial resolution } \\
\sim 0.00833333 \text { decimal degrees (approx. } \\
1 \mathrm{~km} \text { at the equator). }\end{array}$ & Steele et al. 2017 \\
\hline $\begin{array}{l}\text { Higher education } \\
\text { percentage }\end{array}$ & $\begin{array}{l}\text { Percentage of adults who have completed } \\
\text { university at Upazila (Smallest } \\
\text { administrative unit) level. } \\
\text { Dataset derived from ' } 2011 \text { Census of } \\
\text { Population and Housing'. }\end{array}$ & $\begin{array}{l}\text { Bangladesh Bureau } \\
\text { of Statistics 2011, } \\
\text { Minnesota } \\
\text { Population Center } \\
2015\end{array}$ \\
\hline
\end{tabular}




\section{ADDIITONAL LITERATURE CITED}

Bangladesh Bureau of Statistics. 2011. Population and housing Census, Bangladesh. [online] URL: http://www.bbs.gov.bd/

Blair, R. B. 1996. Land use and avian species diversity along an urban gradient. Ecological Applications 6: 506-519.

Brown de Colstoun, E.C., C. Huang, P. Wang, J. C. Tilton, B. Tan, J. Phillips, S. Niemczura, P-Y. Ling and R. E. Wolfe. 2017. Global Man-made Impervious Surface (GMIS) Dataset from Landsat. Palisades, NY: NASA Socioeconomic Data and Applications Center (SEDAC). doi: https://doi.org/10.7927/H4P55KKF

Broxton, P.D., X. Zeng, W. Scheftic, and P. A. Troch. 2014. A MODIS-Based 1 km Maximum Green Vegetation Fraction Dataset, Journal of Applied Meteorology and Climatology. [online] URL: http://dx.doi.org/10.1175/JAMC-D-13-0356.1

Fischer, J.D., S.C. Schneider, A. A. Ahlers, and J.R. Miller. 2015. Categorizing wildlife responses to urbanization and conservation implications of terminology. Conservation Biology 29(4):1246-1248.

Minnesota Population Center. 2015. Integrated Public Use Microdata Series (IPUMS), International: Version 6.4 [dataset]. Minneapolis: University of Minnesota. Available from the Integrated Public Use Microdata Series project. [online] URL: http://doi.org/10.18128/D020.V6.4

OpenStreetMap contributors. 2018. Dhaka, Bangladesh OSM polygons. Retrieved on 01.01.2018. [online] URL: https://planet.openstreetmap.org

Rodewald, A. D., and S. D. Gehrt. 2014. Wildlife population dynamics in urban landscapes. In: Robert A. McCleery, Christopher E. Moorman, M. Nils Peterson (eds), Urban Wildlife Conservation, Theory and Practice, Chapter 8, pp:132-133. Springer, New York.

Steele, J. E. et al. 2017. Mapping poverty using mobile phone and satellite data. J. R. Soc. Interface 14, 20160690. [online] URL: http://rsif.royalsocietypublishing.org/content/14/127/20160690

Tuanmu, M.N., and W. Jetz. 2015. A global, remote sensing-based characterization of terrestrial habitat heterogeneity for biodiversity and ecosystem modelling. Global Ecology and Biogeography. [online] URL: https://doi.org/10.1111/geb.12365

WorldPop. 2017. Bangladesh 100m Population, Version 2. University of Southampton. DOI: $10.5258 / \mathrm{SOTON} / \mathrm{WP} 00533$. 
Appendix 2. RESULTS

Please click here to download file 'appendix2.xlsx'. 


\title{
Appendix 3
}

\author{
RESULTS
}

\section{Bird diversity}

Bird distribution in urban settings varied among species (Table A3.1). The relative abundance of Corvus splendens, and Columba livia peaked in highly urbanized areas (i.e., locations containing impervious surface $>80 \%$ ), matching the pattern for urban dependent birds. These two birds made up $17.8 \%$ of the total bird occurrence in the city. We classified 14 species (i.e., abundant/common) as urban exploiters. Among these, Passer domesticus, Copsychus saularis and Apus nipalensis were widespread throughout. Acridotheres tristis, Cypsiurus balasiensis, Dendrocopos macei, Dinopium benghalense, Egretta garzetta, Halcyon smyrnensis, Haliastur indus, Milvus migrans, Psittacula krameria, Sturnia malabarica, Psilopogon haemacephalus were relatively abundant in intermediate/suburban areas (i.e., locations containing impervious surface between $>30 \%$ and $<80 \%$ ) and urban green areas. These birds accounted for $48.8 \%$ of the total bird occurrences. The remaining 32 species were classified as urban tolerant, mostly observed in lightly urbanized areas/ urban green areas, and they accounted for $33.4 \%$ of the total bird records in the city.

Table A3.1 List of observed bird species and their pattern across urban areas in Dhaka city.

\begin{tabular}{|c|c|c|c|c|}
\hline Scientific name & $\begin{array}{l}\text { Frequency } \\
\text { of } \\
\text { occurrence }\end{array}$ & $\begin{array}{l}\text { Relative } \\
\text { abundance }\end{array}$ & $\begin{array}{c}\text { Pattern across urban } \\
\text { areas }\end{array}$ & Urban affinity \\
\hline Corvus splendens & 161 & 0.1997 & 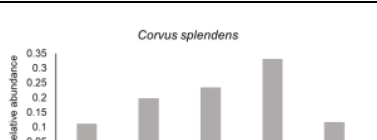 & $\begin{array}{l}\text { Urban } \\
\text { dependend }\end{array}$ \\
\hline Passer domesticus & 159 & 0.1808 & $\begin{array}{l}\text { Passer domessicus } \\
\text { nas }\end{array}$ & Urban exploiter \\
\hline Acridotheres tristis & 98 & 0.0867 & 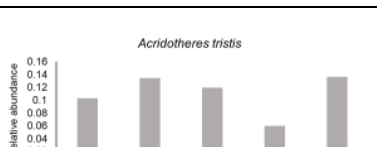 & Urban exploiter \\
\hline Milvus migrans & 90 & 0.0829 & 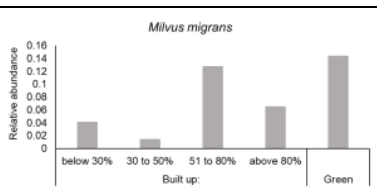 & Urban exploiter \\
\hline
\end{tabular}




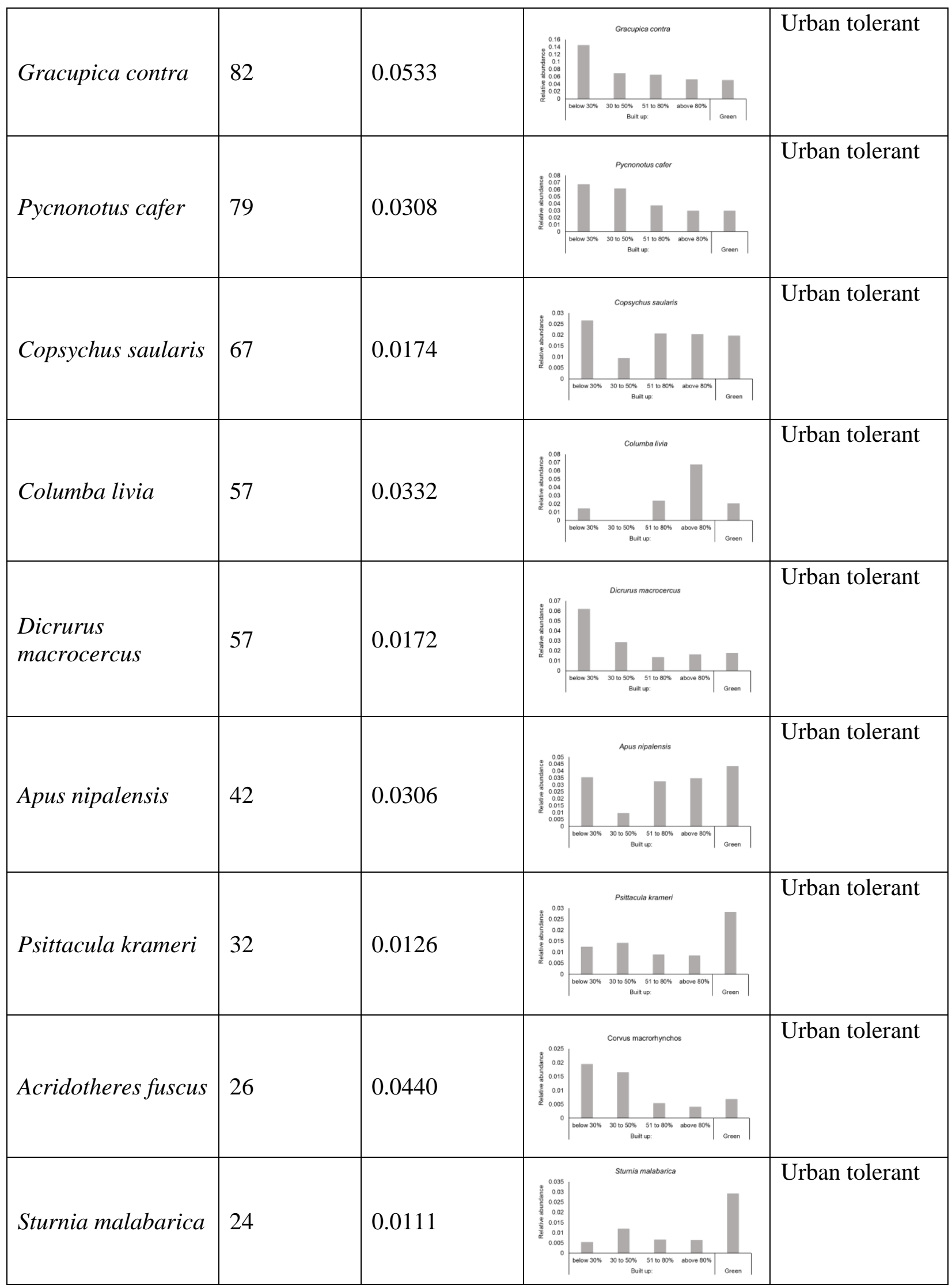




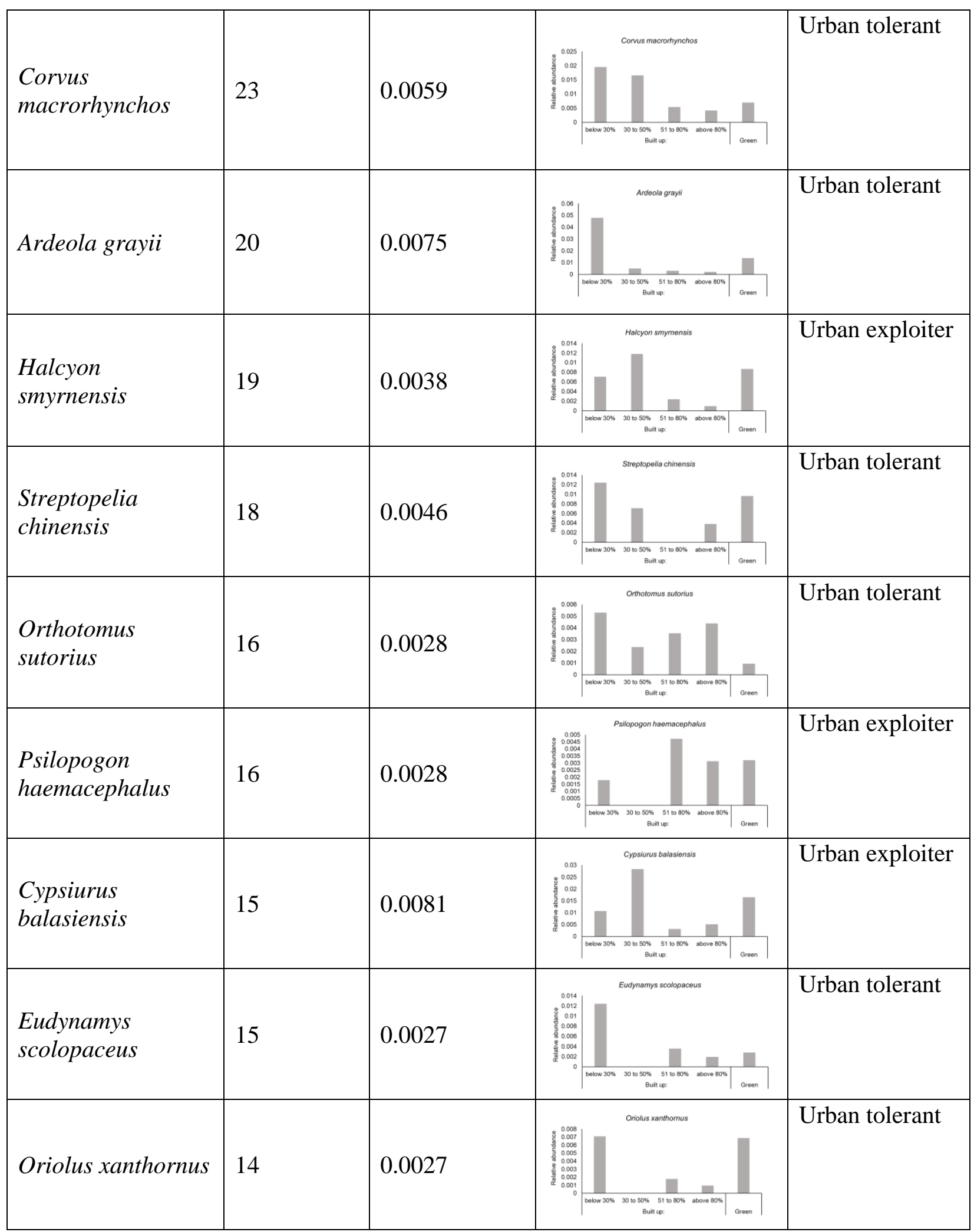




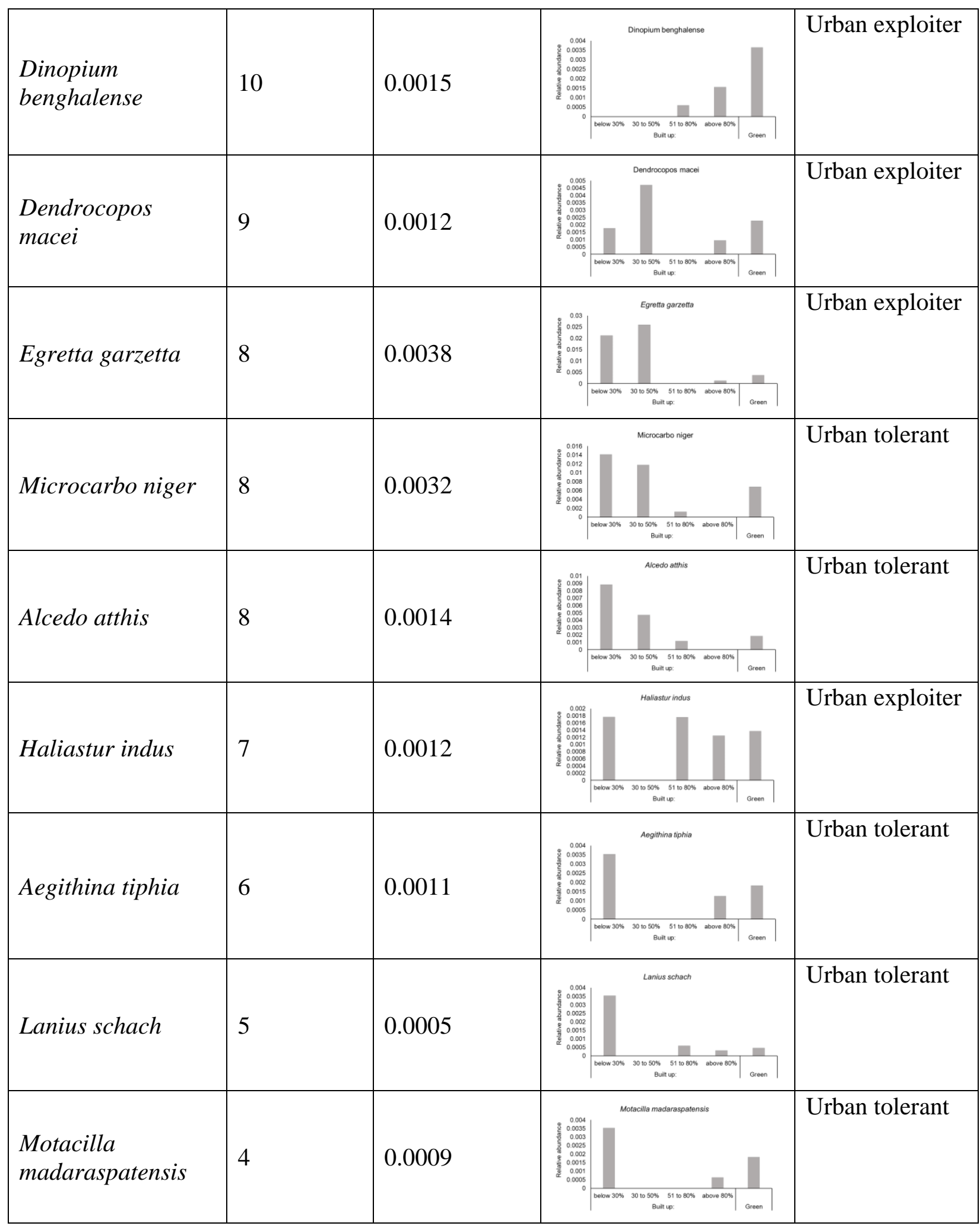




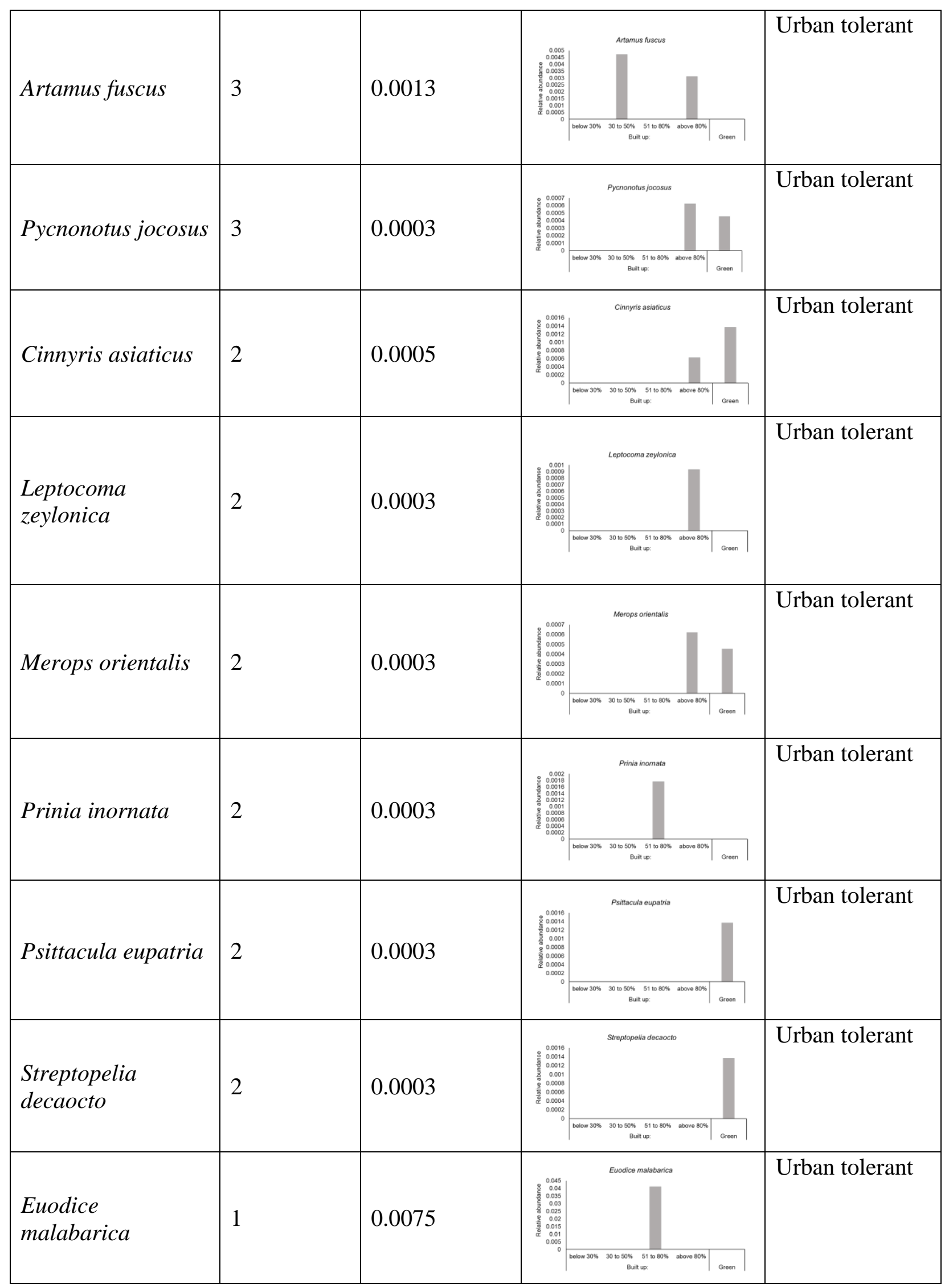




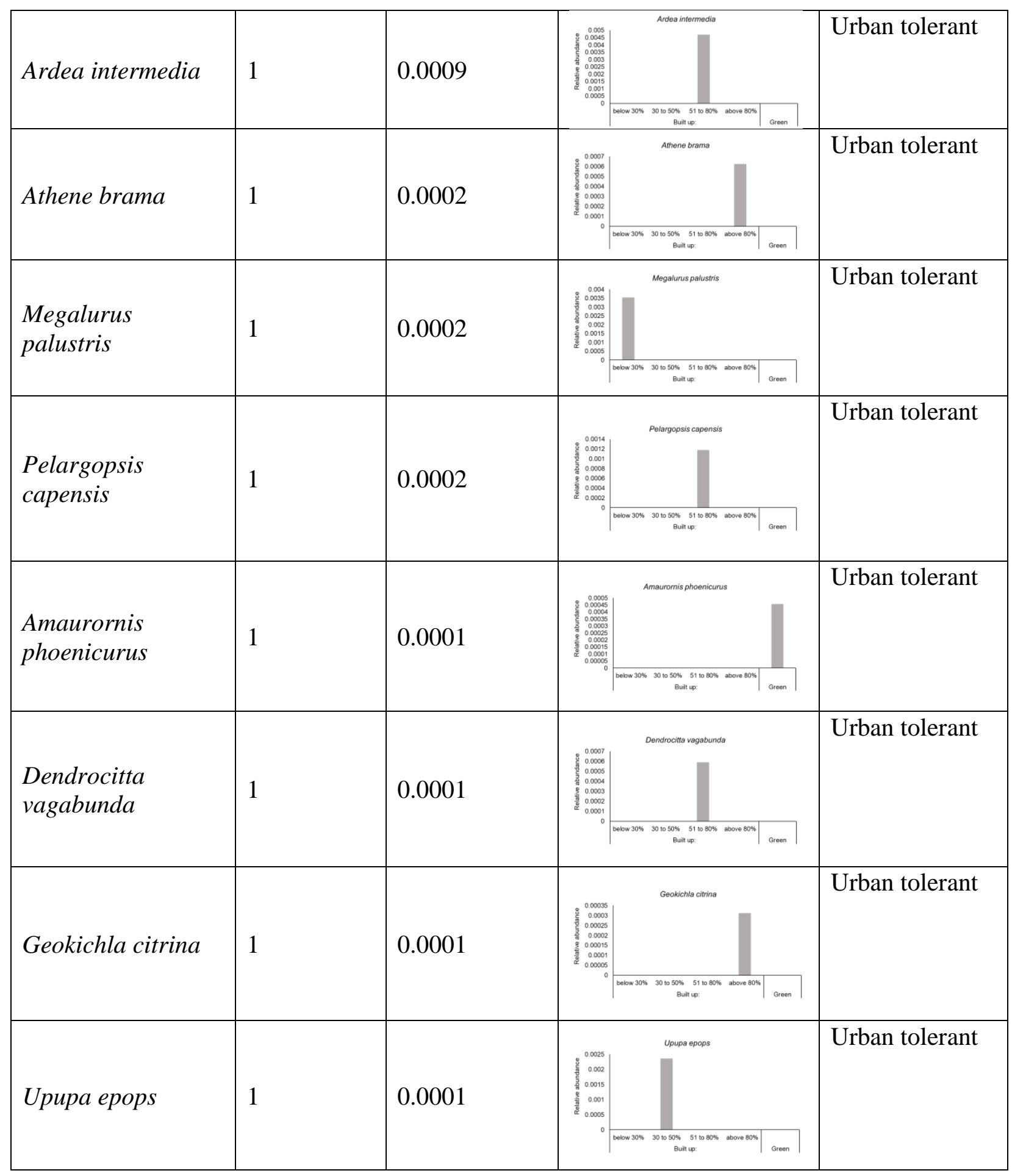




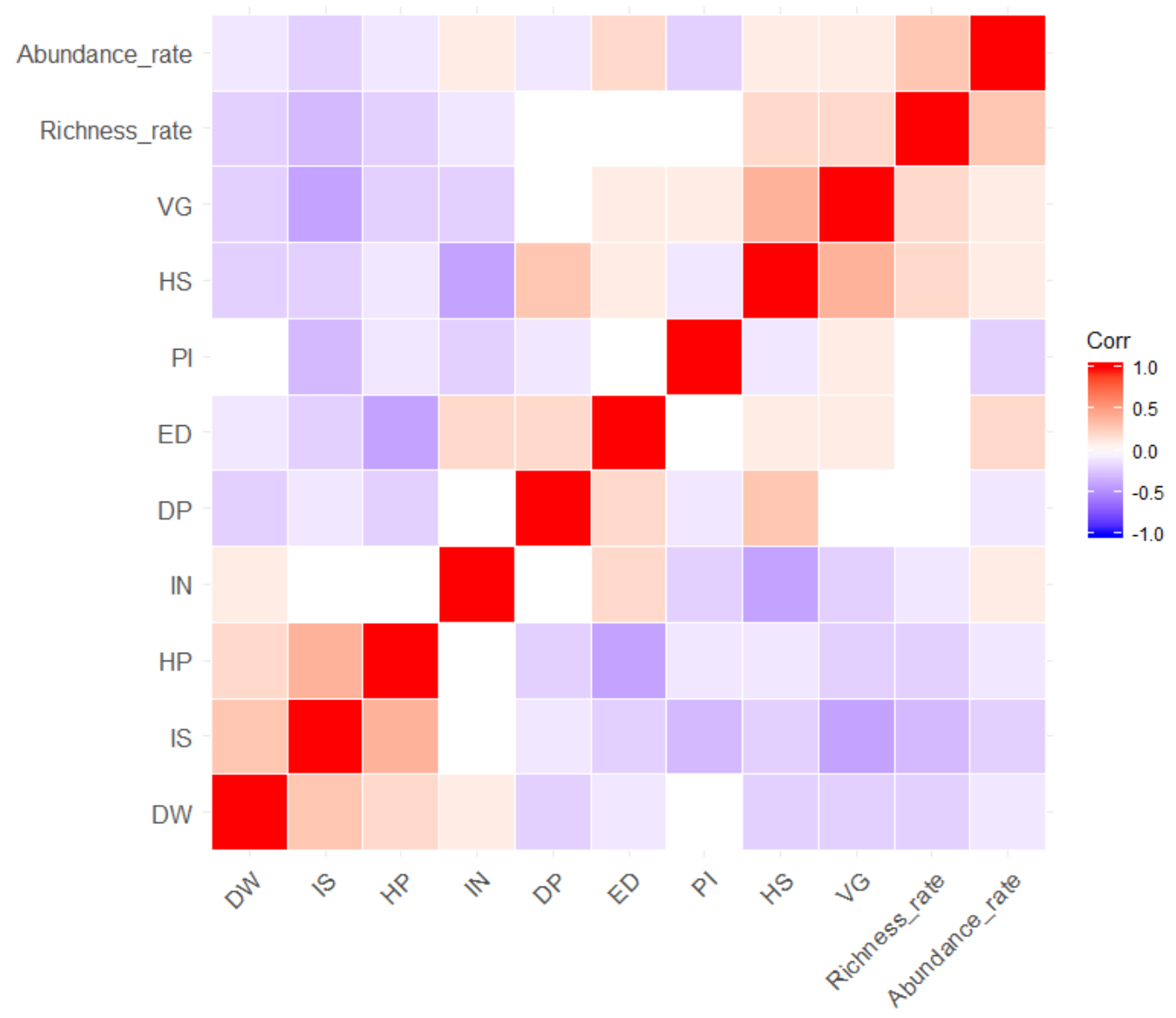

Figure A3.1. Visualisation of correlation matrix among the variables using hierarchical clustering. Here, IS = percentage of impervious surface, HS = habitat Shannon metric representing habitat heterogeneity, $\mathrm{DP}=$ distance to nearest parks $\mathrm{DW}=$ distance to nearest waterbody, $\mathrm{VG}$ = percentage of vegetation, $\mathrm{HP}=$ human population (number per hectare), $\mathrm{PI}=$ poverty index ratio, IN= household income (in USD), ED = Percentage of people with higher education. 

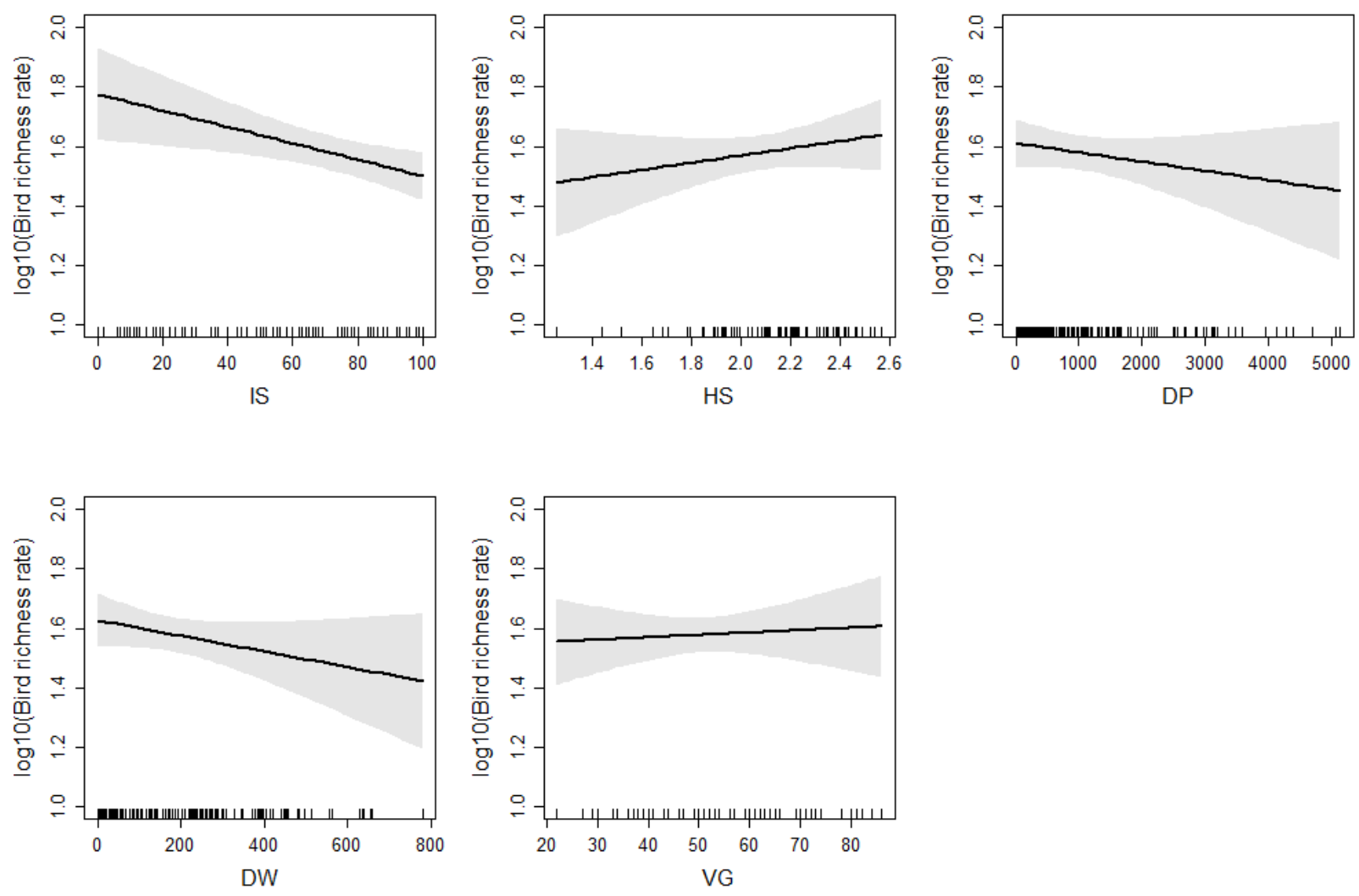

Figure A3.2 Fitted relationship of bird richness rate with different urban land cover variable in the top ranked model. Here, IS = percentage of impervious surface, HS = habitat Shannon metric representing habitat heterogeneity, $\mathrm{DP}=$ distance to nearest parks (in meter), DW = distance to nearest waterbody sites (in meter), VG = percentage of vegetation. 

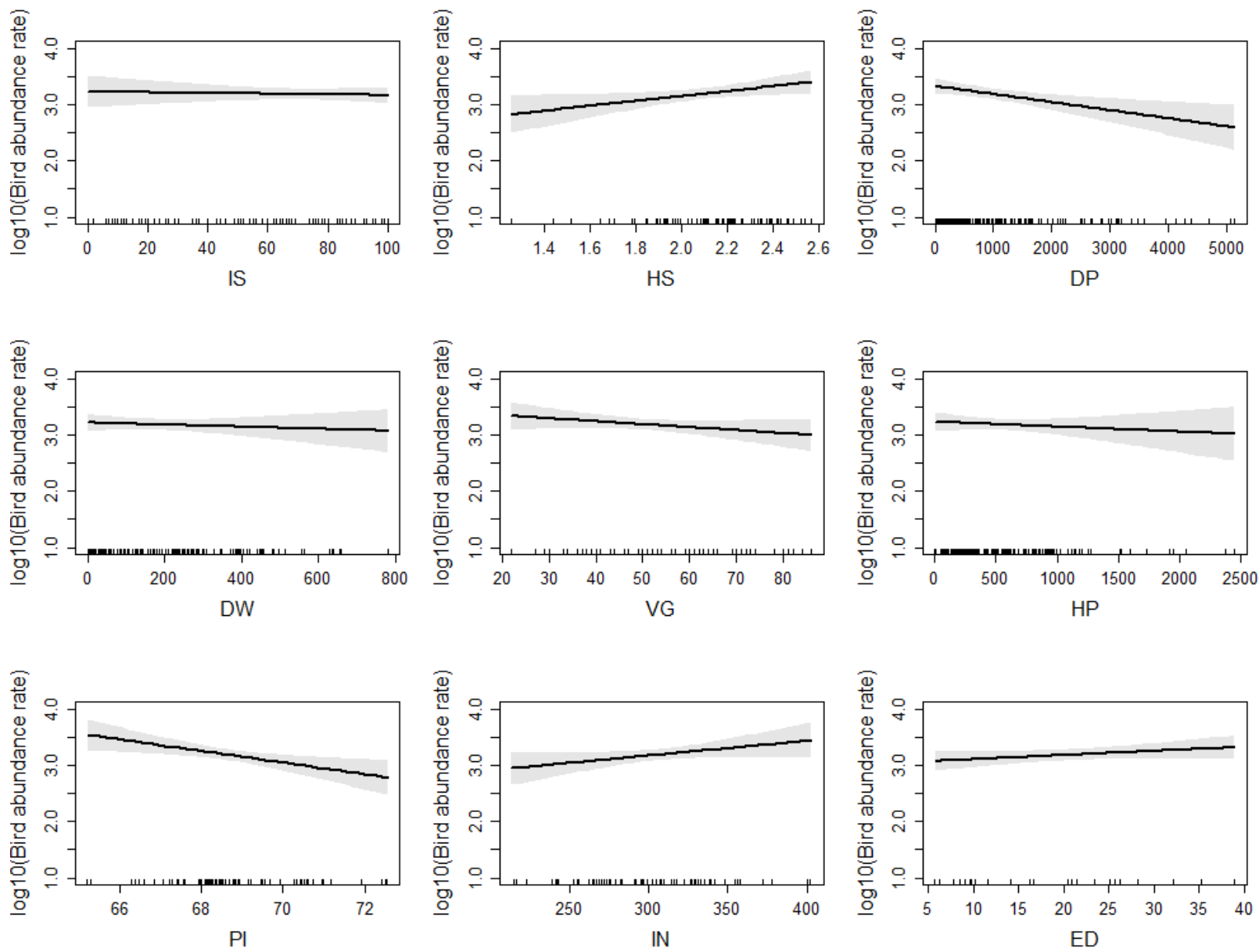

Figure A3.3 Fitted relationship of bird abundance rate with different variables related to land cover and socioeconomic status in the top ranked model. Here, IS = percentage of impervious surface, HS = habitat Shannon metric representing habitat heterogeneity, DP = distance to nearest parks DW $=$ distance to nearest waterbody, $\mathrm{VG}=$ percentage of vegetation, $\mathrm{HP}=$ human population (number per hectare), $\mathrm{PI}$ = poverty index ratio, $\mathrm{IN}=$ household income (in USD), ED = Percentage of people with higher education. 


\section{Appendix 4}

\section{DISCUSSION}
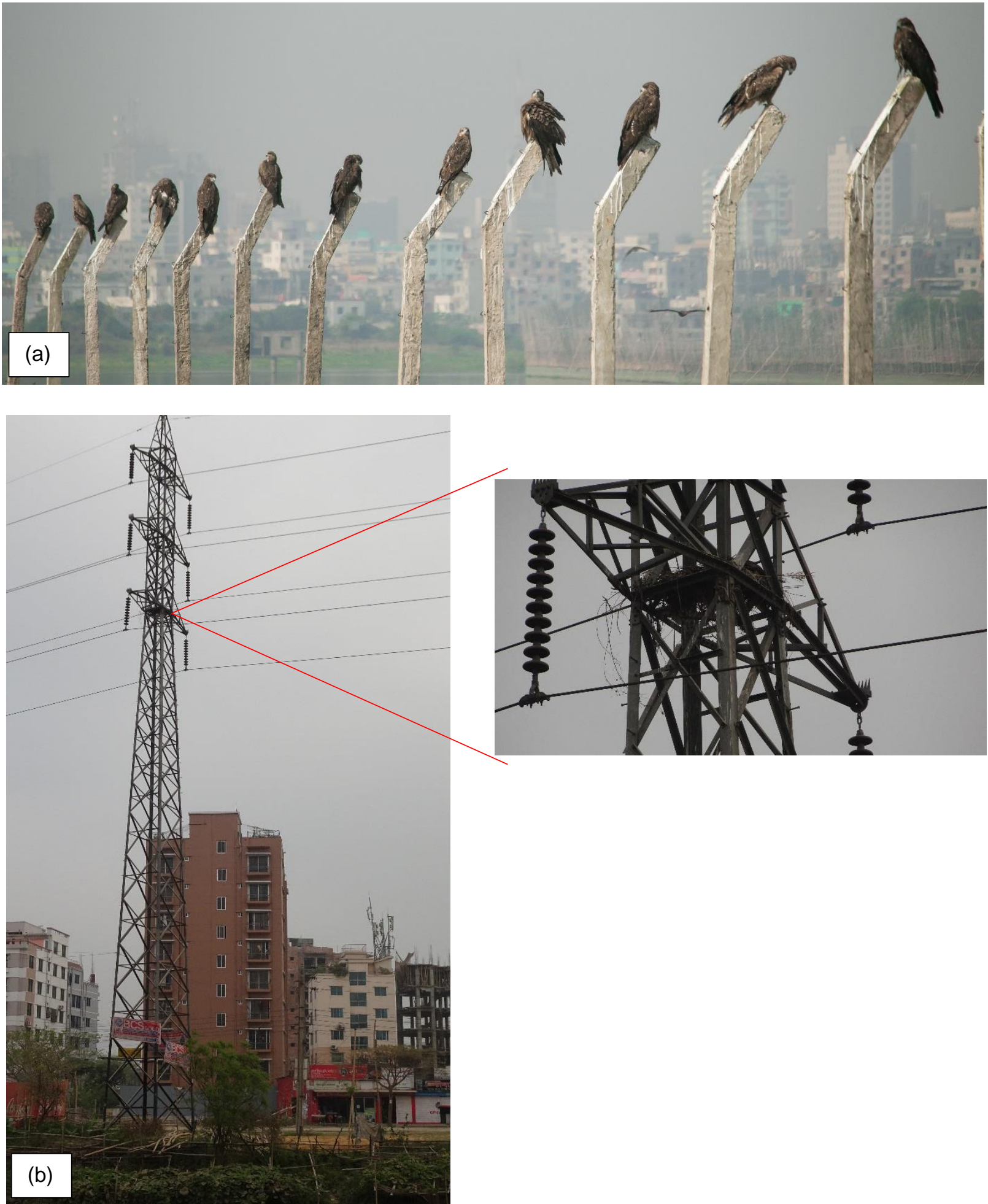

Image A4.1: The case of Milvus migrans, a common species in Dhaka (a), which uses human structures such as electric poles (b) as nesting sites. Picture (a) by Sultan Ahmed; (b) by the authors. 

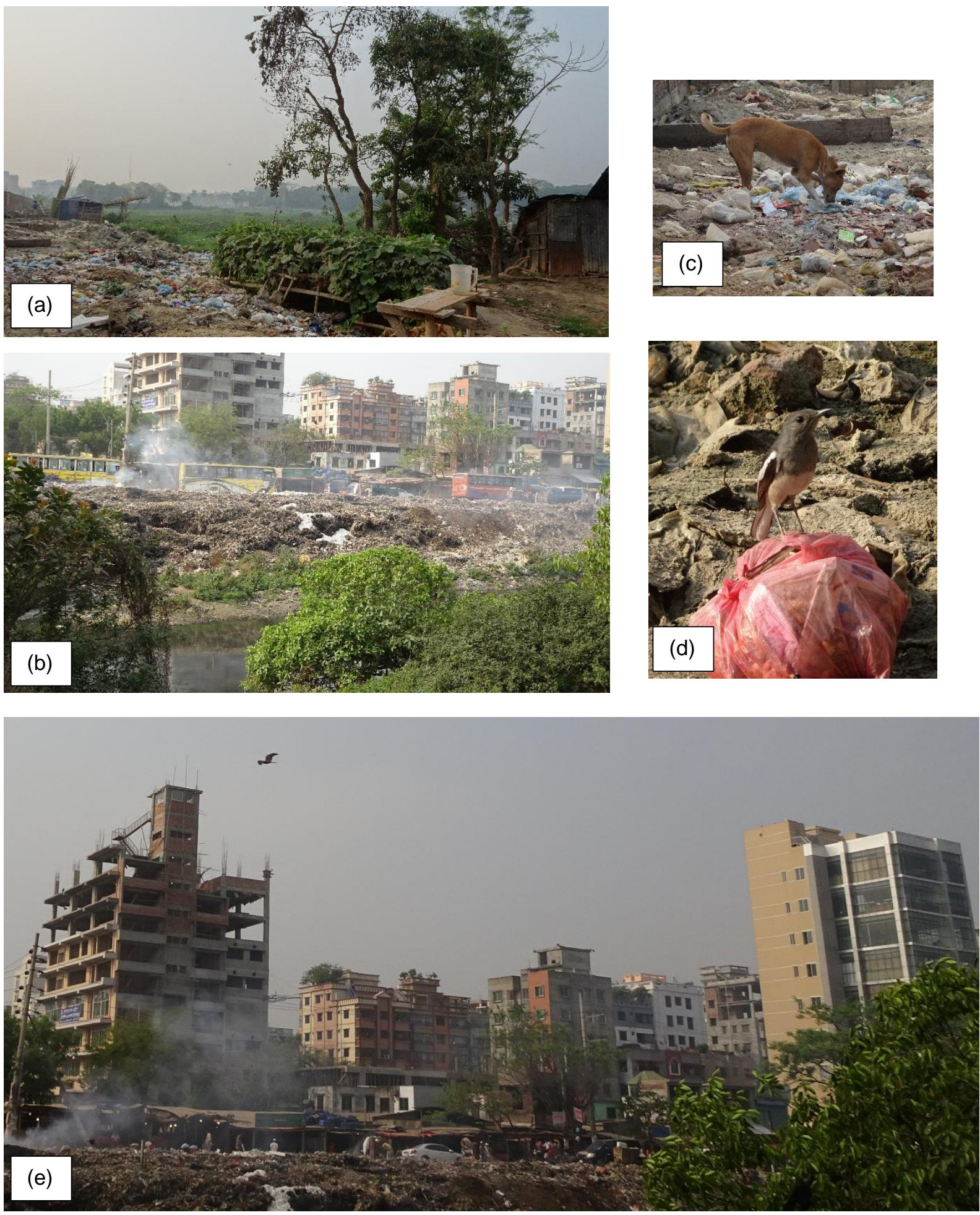

Image A4.2: Pictures (a) and (b) show open dumping places in Dhaka city, (c), (d) and (e) show animals in these areas. Picture (d) taken by Humayra Mahmud, all others by the authors. 


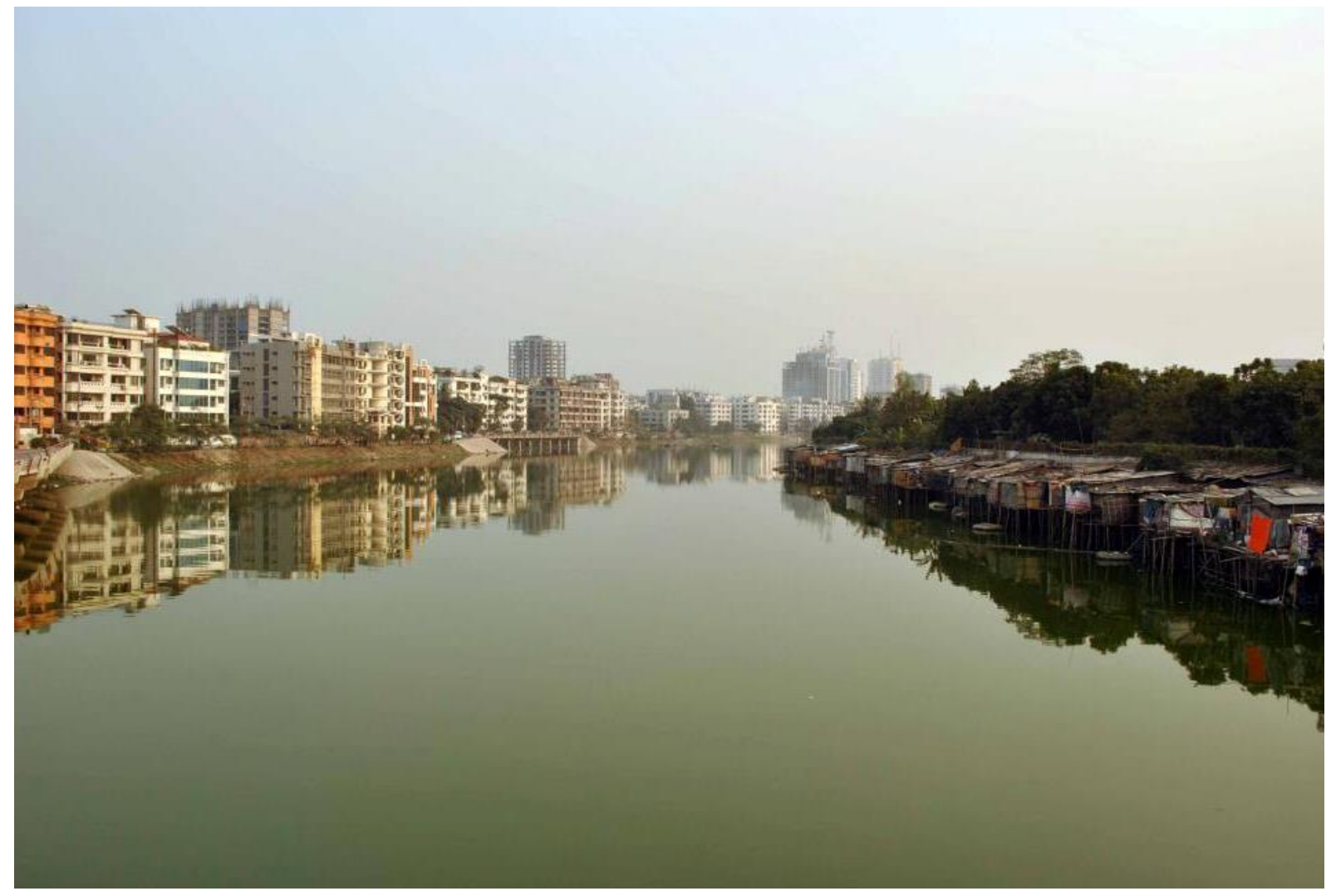

Image A4.3: An example of the variation in socioeconomic status in Dhaka city. Poor people live in slums, whereas people with higher income live in high ranging buildings in a wellmaintained neighborhood. Picture taken by Fahad Noor Promi. 

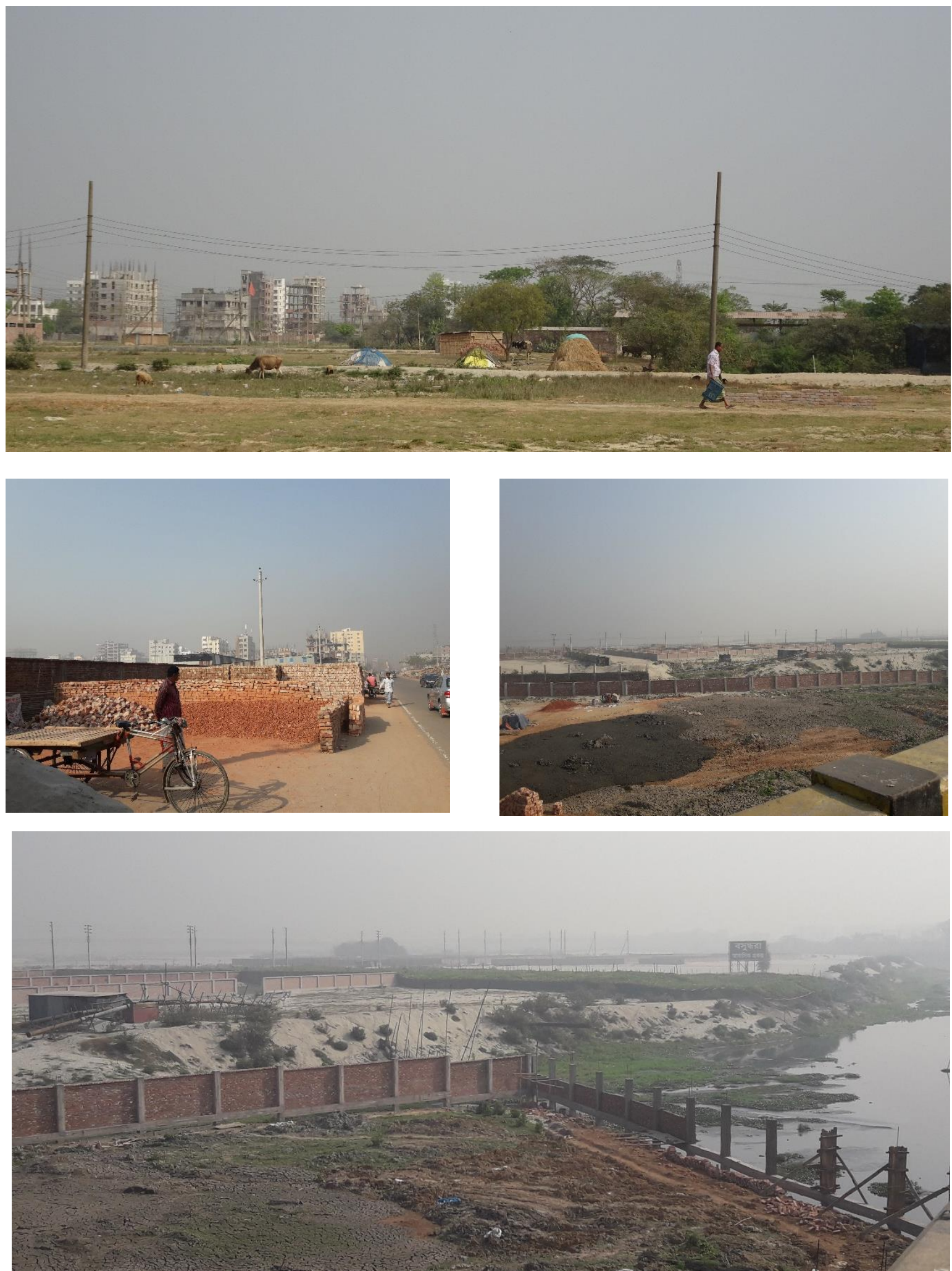

Image A4.4: The pictures show highly disturbed areas at the outskirts of Dhaka city. Due to the rapid expansion of housing infrastructure, agricultural areas and other vegetated sites are declining. All pictures taken by the authors. 